\title{
Reexamination of a primitive ornithomimosaur, Garudimimus brevipes Barsbold, 1981 (Dinosauria: Theropoda), from the Late Cretaceous of Mongolia
}

\author{
Yoshitsugu Kobayashi and Rinchen Barsbold
}

\begin{abstract}
The holotype of Garudimimus brevipes, discovered from the Upper Cretaceous sediments of Mongolia and named by Barsbold in 1981, is redescribed in detail in this paper. Reexamination of the holotype reveals a great deal of anatomical information, which allows us to revise the original diagnosis of this taxon and make comparisons with other ornithomimosaur taxa to understand the evolution of ornithomimosaurs. This paper suggests that characters used to differentiate this taxon in the original paper (short ilia, short metatarsals, exposure of the proximal end of metatarsal III, presence of pedal digit I, and absence of pleurocoels) are not apomorphies but represent the primitive conditions in ornithomimosaurs and are symplesiomorphies. Revised diagnoses are assigned for G. brevipes (posteriorly positioned jaw articulation, fossae at base of dorsal process of supraoccipital, paired depressions on neural spines of proximal caudal vertebra, and deep groove on lateral surface of pedal phalanges III-1 and III-2). Metatarsals of Garudimimus display a non-arctometatarsalian condition as in an Early Cretaceous form, Harpymimus, but the constriction of metatarsal III in Garudimimus is intermediate between Harpymimus and the arctometatarsalian condition in Gallimimus and other derived ornithomimosaurs (ornithomimids). Garudimimus is the only non-ornithomimid ornithomimosaur with edentulous jaws, which were probably covered by rhamphothecae. The loss of teeth with evolution of rhamphothecae and development of a cutting edge in the dentary of Garudimimus suggest the acquisition of feeding habits that included plucking food at the anterior portion of the jaw and cutting at the middle portion, similar to ornithomimids.
\end{abstract}

Résumé : L'holotype de Garudimimus brevipes, découvert dans des roches sédimentaires du Crétacé supérieur de Mongolie et nommé par Barsbold en 1981, est décrit à nouveau en détail. Un nouvel examen de l'holotype révèle une quantité considérable d'information anatomique qui permet de réviser l'interprétation taxonomique originale et de comparer le spécimen à d'autres taxons des ornithomimosaures afin de mieux comprendre leur évolution. Il est suggéré que les caractères utilisés pour distinguer ce taxon dans l'article original (la faible longueur des os iliaques et des métatarsiens, l'exposition de l'extrémité proximale du métatarsien III, la présence du doigt I du pied et l'absence de cavités pleurocoeles) ne sont pas des caractères apomorphiques, mais bien des caractères primitifs et symplésiomorphes des ornithomimosaures. Des diagnostics révisés sont attribués à Garudimimus brevipes (articulation mandibulaire en position postérieure, fosses à la base du processus dorsal du supraoccipital, dépressions en paire sur les neurépines des vertèbres caudales proximales et rainure profonde sur la surface latérale des phalanges III-1 et III-2 du pied). Les métatarsiens de Garudimimus présentent un caractère non-arctométatarsalien semblable à celui d'Harpymimus, du Crétacé précoce, mais la constriction du métatarsien III chez Garudimimus est intermédiaire entre le caractère arctométatarsalien chez Harpymimus et chez Gallimimus ainsi que d'autres ornithomimosaures dérivés (ornithomimidés). Garudimimus est le seul ornithomimosaure non ornithomimidé présentant des mâchoires édentées, qui étaient probablement couvertes de matière cornée. La perte des dents et le développement du revêtement corné et d'une commissure dans le dentaire de Garudimimus suggèrent l'acquisition d'habitudes alimentaires comprenant l'extraction de la nourriture avec la partie antérieure de la mâchoire et son découpage dans la partie médiale, à l'instar des ornithomimidés.

[Traduit par la Rédaction]

Received 22 April 2004. Accepted 14 April 2005. Published on the NRC Research Press Web site at http://cjes.nrc.ca on 23 November 2005.

Paper handled by Associate Editor H.-D. Sues.

Y. Kobayashi. ${ }^{1,2}$ Fukui Prefectural Dinosaur Museum, 51-11 Terao, Muroko, Katsuyama, Fukui 911-8601, Japan.

R. Barsbold. Paleontological Center of Mongolian Academy of Sciences, PO Box 260, Ulaan Baatar 210351, Mongolia.

${ }^{1}$ Corresponding author (e-mail: ykobayashi@museum.hokudai.ac.jp).

${ }^{2}$ Present address: Hokkaido University Museum, Hokkaido University, N10, W8, Kita-ku, Sapporo, Hokkaido 060-0810, Japan. 


\section{Introduction}

Garudimimus brevipes, a toothless but primitive ornithomimosaur dinosaur, was discovered in the Bayanshiree Formation (Cenomanian to Turonian; Khand et al. 2000) in the southeastern part of Mongolia (Baishin Tsav, Ömnögov') during the Joint Soviet-Mongolian Paleontological Expedition (Barsbold 1981) (Fig. 1). Barsbold (1981) briefly described this taxon based on a single skeleton with a well-preserved skull and incomplete postcranial material (missing pectoral girdle, forelimbs, and posterior caudal vertebrae) and coined a family, Garudimimidae, which only includes $G$. brevipes. Since the original description of $G$. brevipes, little additional information has been published (Barsbold and Osmólska 1990; Currie 2000; Makovicky et al. 2004), although it is an important taxon for understanding the evolution of derived ornithomimosaurs. Currie and Eberth (1993) interpreted that the conditions in the metatarsals (arctometatarsalian condition and ratios of metatarsals II, III, and IV) of Garudimimus were similar to those of Archaeornithomimus asiaticus and suggested that some of the Archaeornithomimus specimens from the Iren Dabasu Formation of China were Garudimimus.

Ornithomimosauria includes 11 genera (Kobayashi and Lü 2003; Ji et al. 2003). Seven of these genera (Archaeornithomimus, Sinornithomimus, Gallimimus, Anserimimus, Struthiomimus, Ornithomimus, and Dromiceiomimus) belong to Ornithomimidae. Non-ornithomimid ornithomimosaurs include four genera (Pelecanimimus, Shenzhousaurus, Harpymimus, and Garudimimus), and these are toothed and are known from the Early Cretaceous except for Garudimimus (toothless and Late Cretaceous) (Barsbold and Perle 1984; Pérez-Moreno et al. 1994; Ji et al. 2003). The previous phylogenetic analyses of Ornithomimosauria have consistently suggested that Garudimimus is more derived than toothed ornithomimosaurs and is basal to all members of Ornithomimidae (Barsbold and Osmólska 1990; Osmólska 1997; Kobayashi and Lü 2003; Makovicky et al. 2004; Kobayashi and Barsbold 2004), indicating that Garudimimus is an intermediate form between the Early Cretaceous taxa and Ornithomimidae. Despite its significance to the evolution of Ornithomimosauria, its anatomy is not well described yet.

Barsbold (1981) diagnosed G. brevipes by short ilia, short metatarsals, exposure of the proximal end of metatarsal III, presence of pedal digit I, and absence of pleurocoels (Barsbold 1981). Currie (2000) suggested that there are some possible unique characters for $G$. brevipes, such as a long postorbital region of the skull and a jaw articulation positioned more posteriorly than the postorbital bar. This paper redescribes the holotype of G. brevipes (GIN 100/13) and compares it to other ornithomimosaurs to understand its anatomy in detail and to revise the possible diagnosis for the taxon by Barsbold and Currie.

\section{Institutional abbreviations}

AMNH, American Museum of Natural History, New York, N.Y., USA; GIN, Paleontological Center of Mongolia, Ulaan Bataar, Mongolia; IVPP, Institute of Vertebrate Paleontology and Paleoanthropology, Beijing, China; ROM, Royal Ontario Museum, Toronto, Ontario, Canada; TMP, Royal Tyrrell
Fig. 1. (A) Map of Mongolia, showing the locality of Garudimimus brevipes (Baishin Tsav) and other Mongolian ornithomimosaurs (Harpymimus from Huren-duh; Gallimimus and Anserimimus from Nemegt). (B) Stratigraphic position of the Bayanshiree Formation and the occurrences of Mongolian ornithomimosaurs (from Khand et al. 2000). LJ, Late Jurassic.

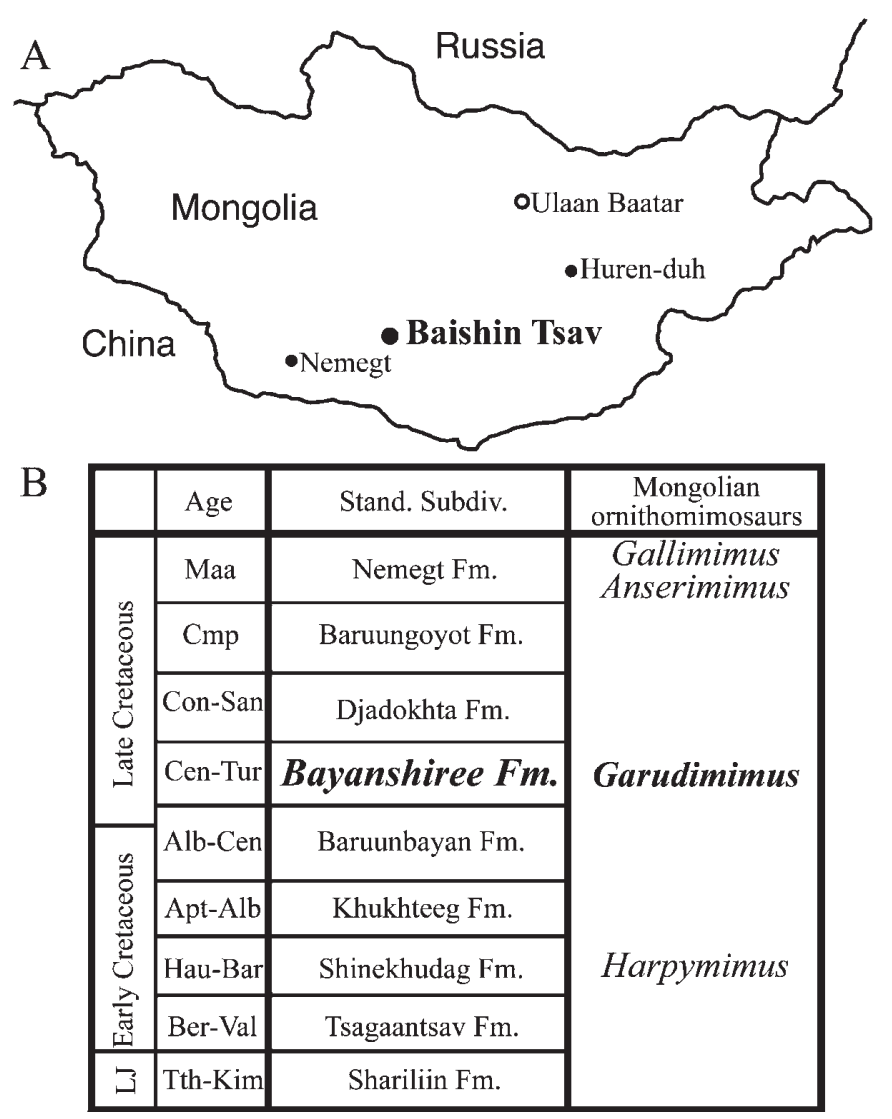

Museum of Palaeontology, Drumheller, Alberta, Canada; UCMZ, Museum of Zoology, University of Calgary, Calgary, Alberta, Canada.

\section{Systematic paleontology}

Theropoda Marsh, 1881

Ornithomimosauria Barsbold, 1976

Garudimimidae Barsbold, 1981

Garudimimus brevipes Barsbold, 1981

HOLOTYPE: GIN 100/13, nearly complete skeleton, missing pectoral girdle, forelimbs, and posterior caudal vertebrae.

TYPE LOCALITY AND HORIzon: Baishin Tsav, Ömnögov', the Bayanshiree Formation (Cenomanian to Turonian; Khand et al. 2000).

EMENDED DIAGNOSIS: Jaw articulation positioned more posterior than the postorbital bar, fossae at base of dorsal process of supraoccipital, paired depressions on lateral surface of neural spines at base of proximal caudal vertebra, and deep groove at proximal end of lateral surface of pedal phalanges III-1 and III-2. 
Fig. 2. Photographs and line drawings of the skull of G. brevipes (GIN 100/13) in right lateral view (A, D), right mandible in lateral view (B, E), and left mandible in medial view (C, F). an, angular; aof, antorbital fenestra; ar, articular; d, dentary; ect, ectopterygoid; emf, external mandibular fenestra; eo, exoccipital; f, frontal; fo, foramen; imf, internal mandibular fenestra; j, jugal; 1, lacrimal; m, maxilla; m.fen, maxillary fenestra; n, nasal; nlc, nasolacrimal canal; oc, occipital condyle; p, parietal; pal, palatine; pf, prefrontal; pm, premaxilla; pm.fen, promaxillary fenestra; po, postorbital; ps, parasphenoid; q, quadrate; qj, quadratojugal; racq, ridge for accessory condyle of quadrate; sa, surangular; sp, splenial; sq, squamosal; stf, supratemporal fenestra.
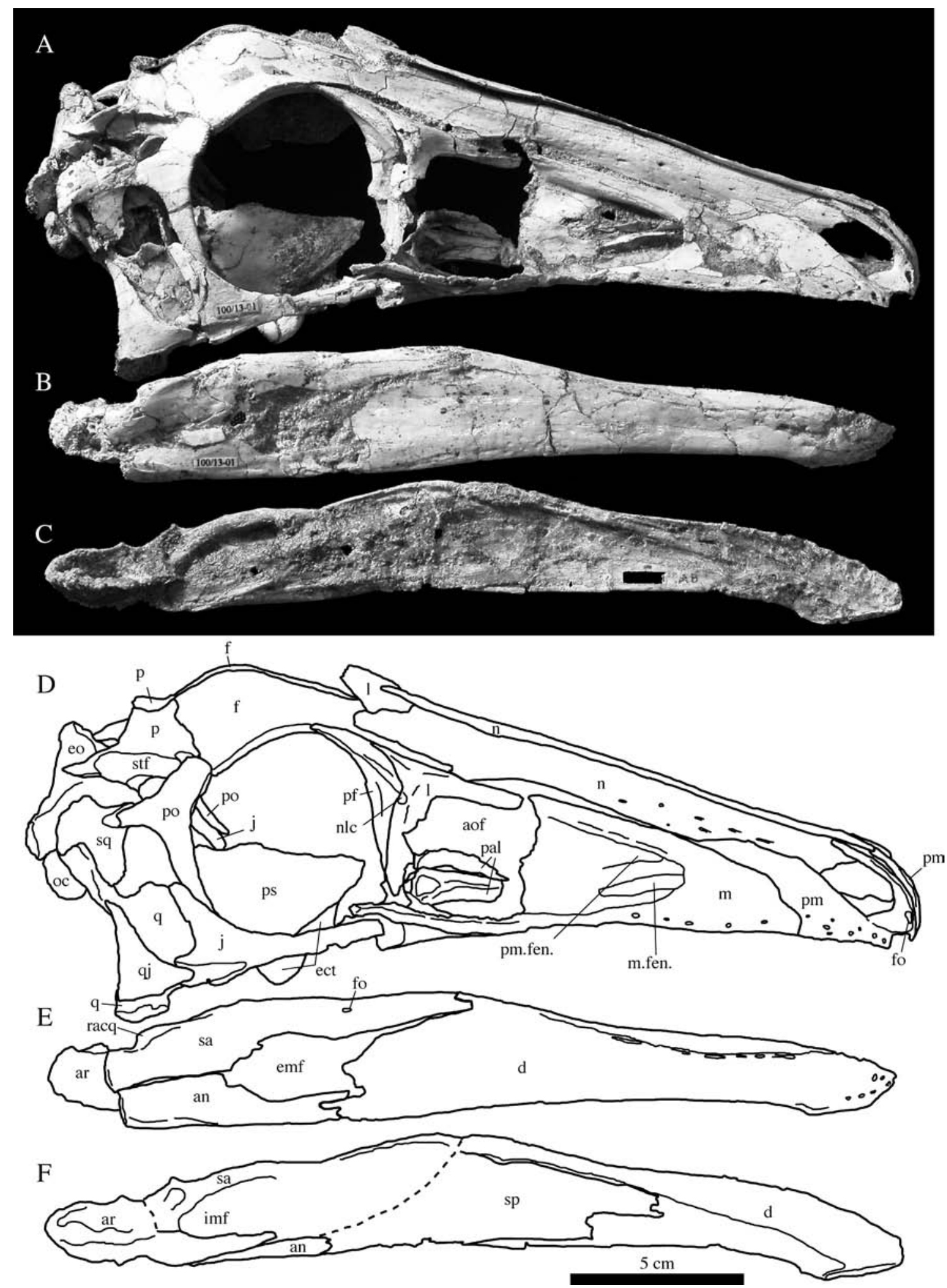
Fig. 3. Photographs and line drawings of the skull of G. brevipes (GIN 100/13) in left lateral view (A, D), left mandible in lateral view (B, E), and right mandible in medial view (C, F). an, angular; ar, articular; bs, basisphenoid; d, dentary; ect, ectopterygoid; emf, external mandibular fenestra; eo, exoccipital; f, frontal; fm, foramen magnum; fo, foramen; imf, internal mandibular fenestra; 1 , lacrimal; m, maxilla; m.fen, maxillary fenestra; n, nasal; nlc, nasolacrimal canal; oc, occipital condyle; p, parietal; pa, prearticular; pal, palatine; pf, prefrontal; pm, premaxilla; pm.fen, promaxillary fenestra; po, postorbital; ps, parasphenoid; pt, pterygoid; pt.h, hook of pterygoid; pt.pr, pterygoid process of quadrate; q, quadrate; qj, quadratojugal; sa, surangular; sc, sclerotic plate; so, supraoccipital; sp, splenial; sq, squamosal; stf, supratemporal fenestra.
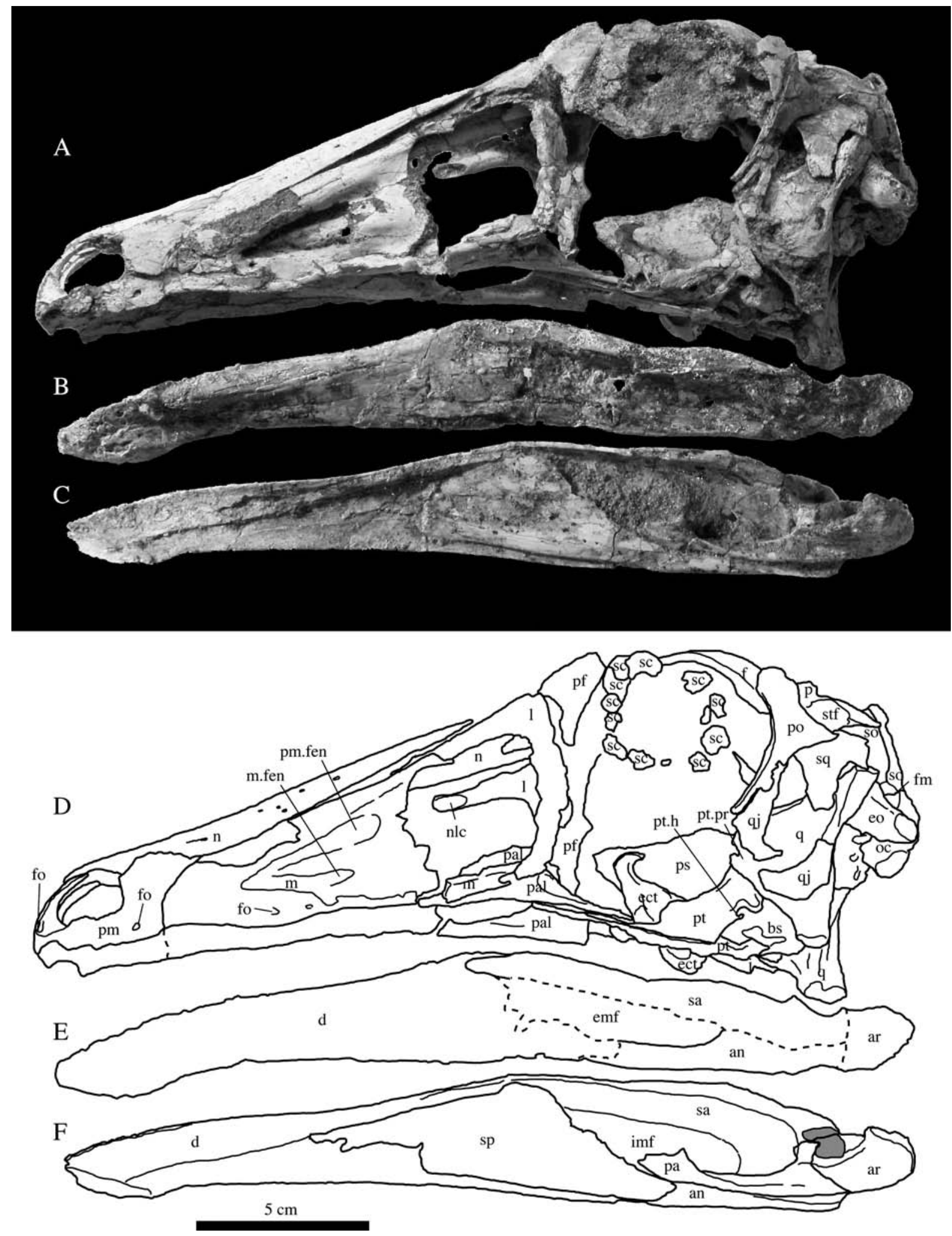
Fig. 4. Photographs and line drawings of the skull of G. brevipes (GIN 100/13) in dorsal (A, D) and ventral (B, E) views and both mandibles in dorsal view (C, F). ar, articular; bo, basioccipital; bs, basisphenoid; d, dentary; ect, ectopterygoid; eo, exoccipital; f, frontal; fo, foramen; if, incisive foramen; $\mathrm{j}$, jugal; 1 , lacrimal; $\mathrm{m}$, maxilla; $\mathrm{n}$, nasal; oc, occipital condyle; p, parietal; pa, prearticular; pal, palatine; pf, prefrontal; pm, premaxilla; pn, pneumatopore; po, postorbital; pt, pterygoid; q, quadrate; qj, quadratojugal; racq, ridge for accessory condyle of quadrate; sa, surangular; so, supraoccipital; sp, splenial; sq, squamosal; stf, supratemporal fenestra; v?, vomer?.
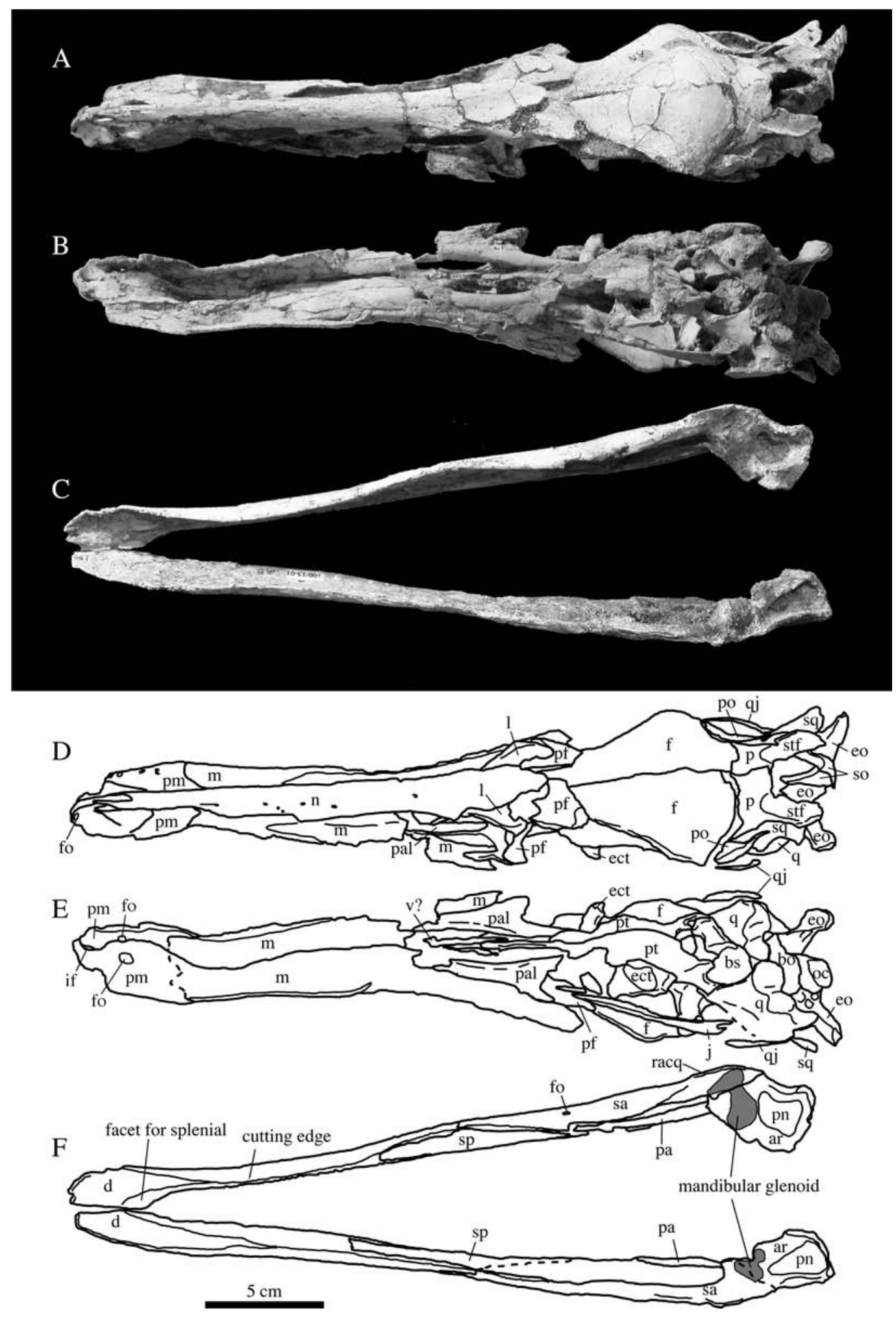


\section{Description}

\section{Skull}

The skull of $G$. brevipes is well preserved and relatively uncrushed, although the left elements are damaged and some elements are displaced slightly (Figs. 2-5; Table 1). The descriptions of most of the skull elements are based on the right side.

\section{Skull openings}

The external narial opening is not divided by an internarial septum (differs from that of Harpymimus okladnikovi (GIN 100/29)) and is separated from the maxilla by the premaxillary-nasal contact. The antorbital fenestra is slightly less than half the length of the antorbital fossa (roughly the same as that in H. okladnikovi (GIN 100/29) and Struthiomimus sp. (TMP 90.26.1) but it is larger in Ornithomimus sp. (TMP 95.110.1)). The supratemporal fenestra is $13.4 \mathrm{~mm}$ long and $6.6 \mathrm{~mm}$ wide, and the supratemporal fossa is $25.1 \mathrm{~mm}$ long and $14.3 \mathrm{~mm}$ wide. The supratemporal fenestra is positioned anteriorly within the supratemporal fossa, differing from that in H. okladnikovi (GIN 100/29) (Kobayashi and Barsbold 2005). The infratemporal fenestra is not well defined because the temporal elements are somewhat displaced; however, the fenestra seems to be large and its middle part is not constricted as in H. okladnikovi (GIN 100/29) (Kobayashi and Barsbold 2005), Ornithomimus sp. (TMP 95.110.1), and Struthiomimus sp. (TMP 90.26.1). The choana is $68.5 \mathrm{~mm}$ long.

\section{Premaxilla}

The edentulous premaxilla borders most of the external narial opening, except for the posterior border. The paired nasal processes narrow posteriorly and wedge between the nasals. There is a foramen at the base of the nasal process as in other ornithomimosaurs (Figs. 2A, 2D, 3A, 3D). In lateral view, the ventral border of the element is straight and lacks the ventral expansion, which is present in Gallimimus bullatus but not H. okladnikovi (GIN 100/29) (Kobayashi and Barsbold 2005). The contact with the maxilla lies posterior to the level of the posterior end of the naris unlike that in $H$. okladnikovi (GIN 100/29). The lateral exposure of the premaxillamaxilla suture is perpendicular to the ventral border of the upper jaw, lacking the short posterior process that is present in Ornithomimus sp. (TMP 95.110.1) and Struthiomimus sp. (TMP 90.26.1). The dorsal end of the maxillary process terminates posterior to the anterior border of the antorbital fossa unlike that in $H$. okladnikovi (GIN 100/29) and Shenzhousaurus orientalis (Ji et al. 2003). A series of foramina is present along the ventral edge of the premaxilla. The palatal shelf of the premaxillae bears the incisive foramen and a pair of foramina, posterior to the incisive foramen, as in an ornithomimosaur from Ukhaa Tolgod of Mongolia (Ksepka and Norell 2004) (Figs. 4A, 4B). The Ukhaa Tolgod ornithomimosaur has another pair of foramina anterior to the incisive foramen, but these foramina may be absent in Garudimimus.

\section{Maxilla}

The lateral surface of the main body of the maxilla, anterior to the antorbital fossa, has a rough surface as in other ornithomimosaurs. Within the antorbital fossa, there are two accessory (promaxillary and maxillary) fenestrae unlike those in S. orientalis (Ji et al. 2003). The dorsal process meets the anterior process of the lacrimal at the mid-length of the antorbital fossa as in H. okladnikovi (GIN 100/29) (Figs. 3A, 3D). In lateral view, the ventral border of the maxilla is straight and lacks the ventral expansion seen in G. bullatus. The ventral edge of the lateral surface has foramina like those in S. orientalis (Ji et al. 2003), Struthiomimus sp. (TMP 90.26.1), and Ornithomimus sp. (TMP 95.110.1).

\section{Nasal}

The nasal is long and forms the posterior border of the external narial opening. It broadens posteriorly, with the maximum breadth at the level of the anterior limit of the lacrimal, behind which it narrows towards the contact with the frontal (Figs. 4A, 4D). The posterior end of the nasal lies between the posterior ends of the prefrontal and lacrimal (it is close to the posterior end of the prefrontal in H. okladnikovi (GIN 100/29) and Struthiomimus altus (TMP 90.26.1) and close to the posterior end of the lacrimal in Ornithomimus sp. (TMP 95.110.1)). The dorsal surface of the nasal has foramina as in other ornithomimosaurs (Russell 1972; Makovicky et al. 2004).

\section{Lacrimal}

The tip of the anterior process of the lacrimal is broken and shows that the anterior process is hollowed by the nasolacrimal canal (Figs. 3A, 3D) as the condition in Dromiceiomimus brevitertius (CMN 12228) (Witmer 1997). The ventral process of the lacrimal is nearly perpendicular to the main axis of the anterior process as in other ornithomimosaurs except Struthiomimus sp. (TMP 90.26.1). The medial surface of the main body of the lacrimal-prefrontal complex has a large triangular-shaped depression. The medial surface of the ventral process of the lacrimal bears the lacrimal recess ventral to the large depression, from which it is separated by a thin vertical lamina. The recess opens anteromedially. The posterolateral surface of the ventral process has a posterior opening for the nasolacrimal canal (Figs. 2A, 2D), which is also seen in Gallimimus sp. (GIN 100/14). The posterior process narrows and inserts into a depression on the prefrontal, as in other ornithomimosaurs.

\section{Prefrontal}

The dorsally exposed area of the prefrontal is slightly smaller than that of the lacrimal, as in H. okladnikovi (GIN 100/29) (Kobayashi and Barsbold 2005) (Figs. 4A, 4D). The prefrontal has an anterior process that contacts the ventral surface of the main body of the lacrimal. The anterior process bifurcates, and the medial branch is much larger than the lateral. In posterior view, the orbital rim of the prefrontal becomes wider ventrally and lacks any foramina. The posterior end of the orbital process of the prefrontal is broken and hollow.

\section{Sclerotic ring}

The left side of the skull preserves 11 articulated scleral plates (Figs. 3A, 3D). The radius of the ring is $26.8 \mathrm{~mm}$ inside the bony elements and $41.2 \mathrm{~mm}$ outside. The breadth of each well-preserved plate is roughly $8 \mathrm{~mm}$. 
Fig. 5. Photographs and line drawings of the skull of G. brevipes (GIN 100/13) in occipital (A, B) and occipitoventral (C, D) views. $\mathrm{X}$, vagus foramen; XII?, foramina for hypoglossal nerve?; bo, basioccipital; bs, basisphenoid; dep, depression; ect, ectopterygoid; eo, exoccipital; f, frontal; fm, foramen magnum; fo, foramen; j, jugal; oc, occipital condyle; p, parietal; po, postorbital; pqf, paraquadratic foramen; pt, pterygoid; q, quadrate; qf, quadrate fossa; qj, quadratojugal; scr, subcondylar recess; so, supraoccipital; sq, squamosal.
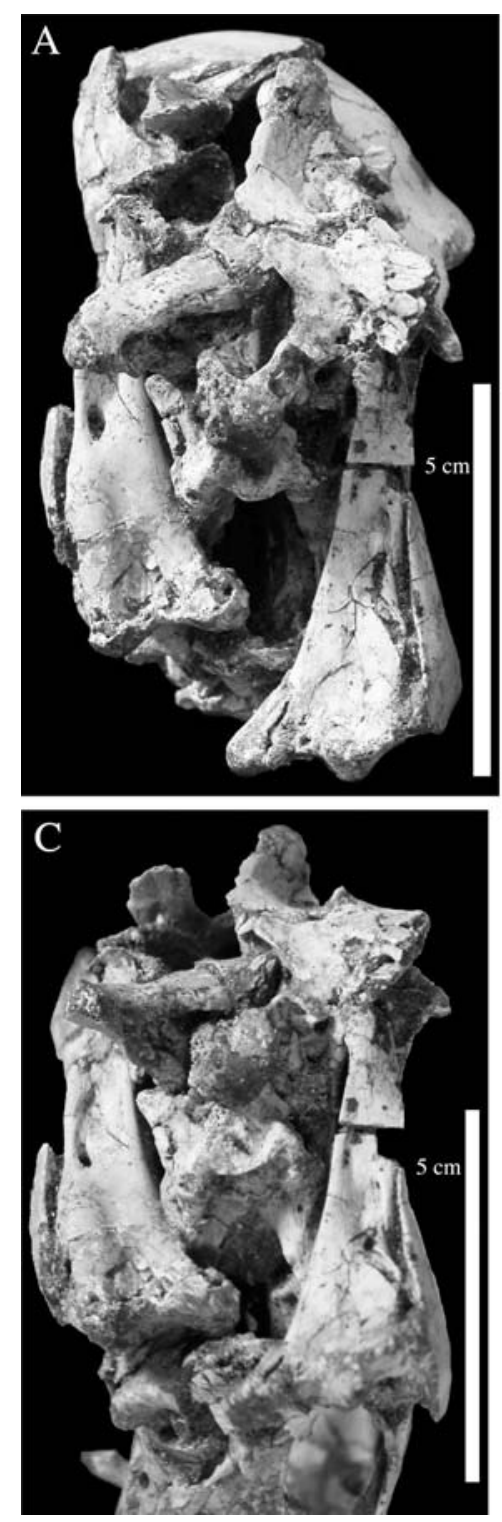

\section{Jugal}

The anterior end of the anterior process of the jugal is not well preserved, and the sutures for the lacrimal and maxilla are not clear. The jugal becomes taller posteriorly. In lateral view, the jugal has a short posterior process (roughly $10 \mathrm{~mm}$ long) (Figs. 2A, 2D). The lateral surface has a shallow depression for contact with the anterior process of the quadratojugal, but this is positioned farther anteriorly than the posterior edge of the orbit. The depression in Struthiomimus sp. (TMP 90.26.1) and Ornithomimus sp. (TMP 95.110.1) extends more anteriorly. The dorsal process thins distally and its lateral surface is flat.

\section{Quadratojugal}

The quadratojugal is large and triangular, in contrast with the L-shaped quadratojugal of the other ornithomimosaurs
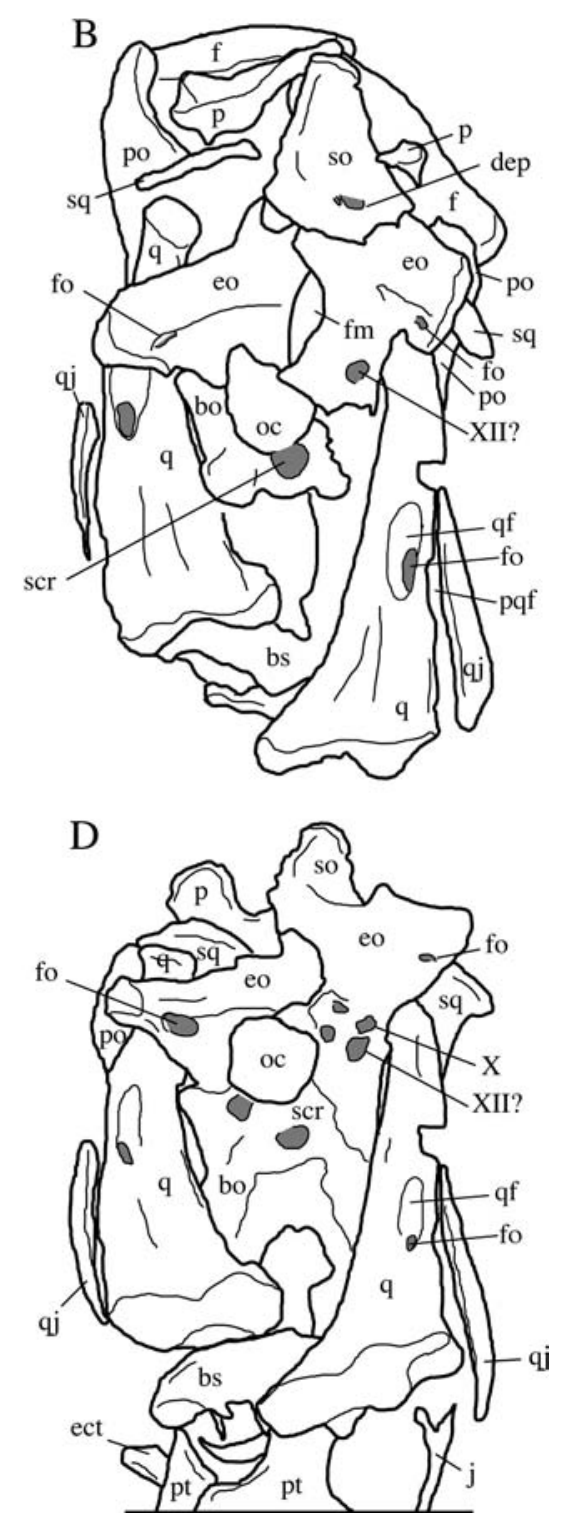

(Figs. 2A, 2D). It does not have a notch for the paraquadrate foramen. Although the tip of the dorsal process is missing, the dorsal process is longer than the anterior process, as in other ornithomimosaurs.

\section{Quadrate}

The quadrate fossa is positioned slightly dorsal to the mid-height of the quadrate (Fig. 5). The depression is oval, $12 \mathrm{~mm}$ long and $4 \mathrm{~mm}$ wide. A foramen is present in the ventral part of the depression. Ventral to the depression, the lateral edge of the quadrate has an embayment for the paraquadrate foramen. The equally sized mandibular condyles are well separated by a sulcus (Figs. 4B, 4E; 5A, 5B). The pterygoid wing is triangular in lateral view and large, at least $29 \mathrm{~mm}$ in anteroposterior length at the level of the quadrate fossa (Figs. 3A, 3D). 


\section{Frontal}

The frontals are triangular in dorsal view (Figs. 4A, 4D). The planar anterior part of the frontals is sloped anteriorly. Posteriorly, the frontals form a single dome (Figs. 5A, 5B) unlike $G$. bullatus, which has a dome on each frontal separated by a midline depression (Osmólska et al. 1972).

\section{Parietal}

Medially, the parietals are flat in the posterior portion of the skull table. The skull table is wider than long (Figs. 4A, 4D) unlike that in Struthiomimus sp. (TMP 90.26.1), in which it is roughly as wide as long. The posterior process is straight and extends posteriorly, whereas the process in Ornithomimus sp. (TMP 95.110.1), Struthiomimus sp. (TMP 90.26.1), and G. bullatus is bent ventrally. The parietal is depressed lateral to the skull table and the posterior process to form the medial part of the supratemporal fossa.

\section{Postorbital}

The anterior process of the postorbital is square and of uniform thickness in lateral view. The postorbital-frontal suture originates at the posterodorsal part of the orbit. The short postorbital-parietal suture extends from the anterior end of the supratemporal fossa to the supratemporal fenestra. The tall ventral process narrows ventrally. The curvature of the anterodorsal border of the infratemporal fenestra is much weaker than in H. okladnikovi (GIN 100/29), Ornithomimus sp. (TMP 95.110.1), and Struthiomimus sp. (TMP 90.26.1) (Figs. 2A, 2D).

\section{Squamosal}

The tips of the ventral and posterior processes of the squamosal are missing (Figs. 2A, 2D, 3A, 3D). The anterior process contacts medially the posterior process of the postorbital. The anterior and ventral processes are tall in lateral view. The base of the posterior process is directed posteriorly. The medial process contacts the parietal and borders the posterolateral edge of the supratemporal fenestra.

\section{Supraoccipital}

The occipital region of $G$. brevipes is transversely crushed. Dorsally, the supraoccipital is flat and lies between the posterior processes of the parietals. The posterior surface has a vertical ridge, as in $S$. altus (AMNH 5355), but unlike that in G. bullatus (Makovicky and Norell 1998) (Figs. 5A, 5B). In dorsal view, the dorsal process is thin and U-shaped (Figs. 4A, 4D). At the base of the dorsal process, there are two small fossae unlike those in other ornithomimosaurs (Figs. 5A, 5B).

\section{Exoccipital}

The paroccipital process extends lateroventrally, and its ventral border is at the level of the foramen magnum (Figs. 5A, 5B). The exoccipital has a large foramen on the posteroventral surface, as in G. bullatus (GIN 100/10 and GIN 100/1133) and Struthiomimus sp. (TMP 90.26.1) (Fig. 5). A posteroventral process, extending from the base of the paroccipital process, borders the lateral side of the foramen magnum and has a foramen on its medial surface, as in an Ukhaa Tolgod ornithomimid (GIN 100/987), Dromiceiomimus samueli (ROM 840), some dromaeosaurids, and Troodon formosus (Currie and Zhao 1994; Makovicky and Norell
Table 1. Measurements (in $\mathrm{mm}$ ) of the skull in the holotype of Garudimimus brevipes (GIN 100/13).

Skull length (premaxilla-squamosal)

252.2

Skull height (excluding mandible) at the orbit $\quad 78.6$

Orbit, anteroposterior length

61.9

Antorbital fossa, length $\times$ height

$82.4 \times 36.0$

Antorbital fenestra, anteroposterior length

Mandibular length

38.2

Mandibular height

246.3

Mandibular fenestra, length $\times$ height

36.4

$38.9 \times 20.3$

Fig. 6. Cervical vertebrae of G. brevipes (GIN 100/13). (A) Axis with articulated atlas in right lateral view. (B) Posterior part of third cervical, fourth cervical, and anterior part of fifth cervical in right lateral view (C). Two posterior (probably seventh and eighth) cervicals in right lateral view. Sixth cervical and partial seventh cervical in left lateral (D) and dorsal (E) views. at, atlas; ati, atlantal intercentrum; cev, cervical vertebra; ns, neural spine; odp, odontid process; prz, prezygapophysis; pz, postzygapophysis.
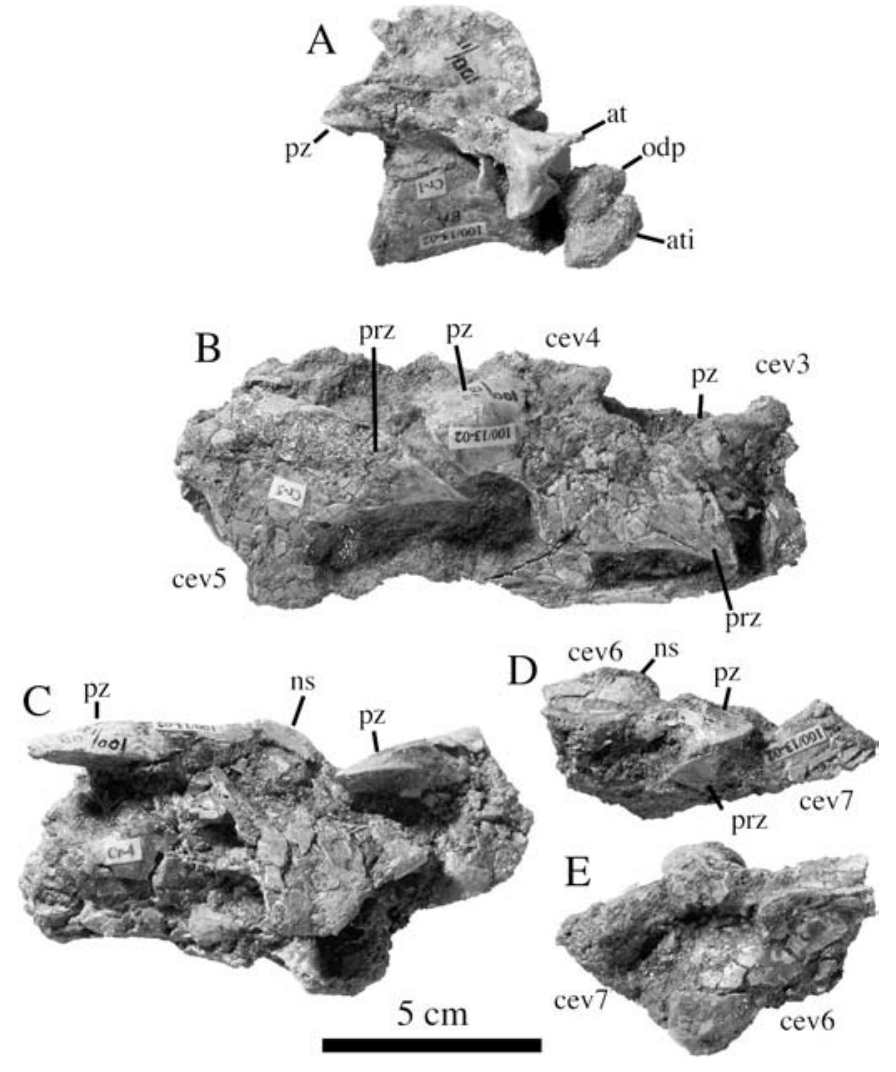

1998). This foramen is identified as an endolymphatic foramen by Currie (1995), but Makovicky and Norell (1998) suggest that it is a foramen associated with the posterior cerebellar venous sinus. A part of the posterolateral process is broken and hollow. Its ventral end forms a dorsal portion of the occipital condyle. Ventrolateral to the occipital condyle is a foramen for the vagus $(\mathrm{X})$ nerve, but the openings for the hypoglossal (XII) nerve are not apparent (Fig. 5). A large recess is present ventral to the opening for the vagus and is probably the subcondylar recess. 
Fig. 7. Anterior dorsal vertebrae of G. brevipes (GIN 100/13): fourth in lateral (A) and ventral (B) views, fifth in lateral (C) and ventral (D) views, and sixth in lateral (E) and ventral (F) views. ns, neural spine; prz, prezygapophysis; pz, postzygapophysis.
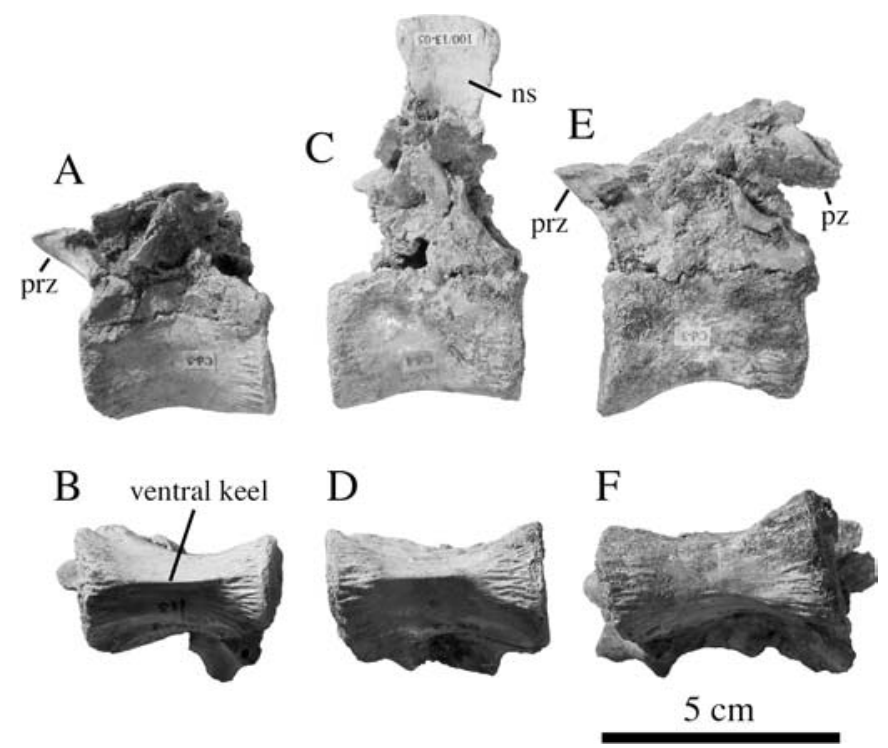

\section{Basioccipital and basisphenoid}

The occipital condyle, partially formed by the basioccipital, is $10.5 \mathrm{~mm}$ high, which is much less than the dorsoventral height of the foramen magnum $(15.7 \mathrm{~mm})$. It is posteroventrally directed and does not have a distinctive neck like that in S. altus (AMNH 5355) and the braincase of an Ukhaa Tolgod ornithomimid (GIN 100/987) described by Makovicky and Norell (1998). Between the basal tubera, there is a noninvasive depression. A small tubercle is known ventral to this depression in the ornithomimid braincase (GIN 100/987), but $G$. brevipes does not have this tubercle. The pterygoid process of the basisphenoid is exposed and is laterally directed, articulating with the hook of the pterygoid (Figs. 3A, 3D).

\section{Parasphenoid}

The parasphenoid is bulbous and laterally flattened. In lateral view, the dorsal edge of this element is straight, and its ventral edge is convex as in G. bullatus and the troodontids Saurornithoides and Troodon (Osmólska et al. 1972; Barsbold 1981; Currie 1985) (Figs. 2A, 2D, 3A, 3D).

\section{Vomer, palatine, pterygoid, and ectopterygoid}

The posterior portion of the vomer may be preserved and borders the medial edge of the choana (Figs. 4B, 4E). The maxillary process of the palatine is thicker than the vomeral process, and these processes form the posterior boundary of the choana. The main body of the palatine is triangular in ventral view and has a fossa (palatine recess) on the dorsal surface as in S. orientalis and some dromaeosaurids (Deinonychus and Velociraptor) (Witmer 1997; Ji et al. 2003) (Figs. 2A, 2D). The pterygoids are positioned ventral to the parasphenoid bulla and are triradiate, with one anterior and two posterior (quadrate and basipterygoid processes) processes (Osmólska et al. 1972). The medial edge of the main body is straight, lacking the basal process. The anterior process of the
Fig. 8. Posterior dorsal vertebrae of G. brevipes (GIN 100/13) in right lateral view: sixth and seventh $(B)$, ninth $(A)$, tenth $(\mathrm{E})$, eleventh (D), and twelfth (C) dorsal vertebrae. prz, prezygapophysis; pz, postzygapophysis.
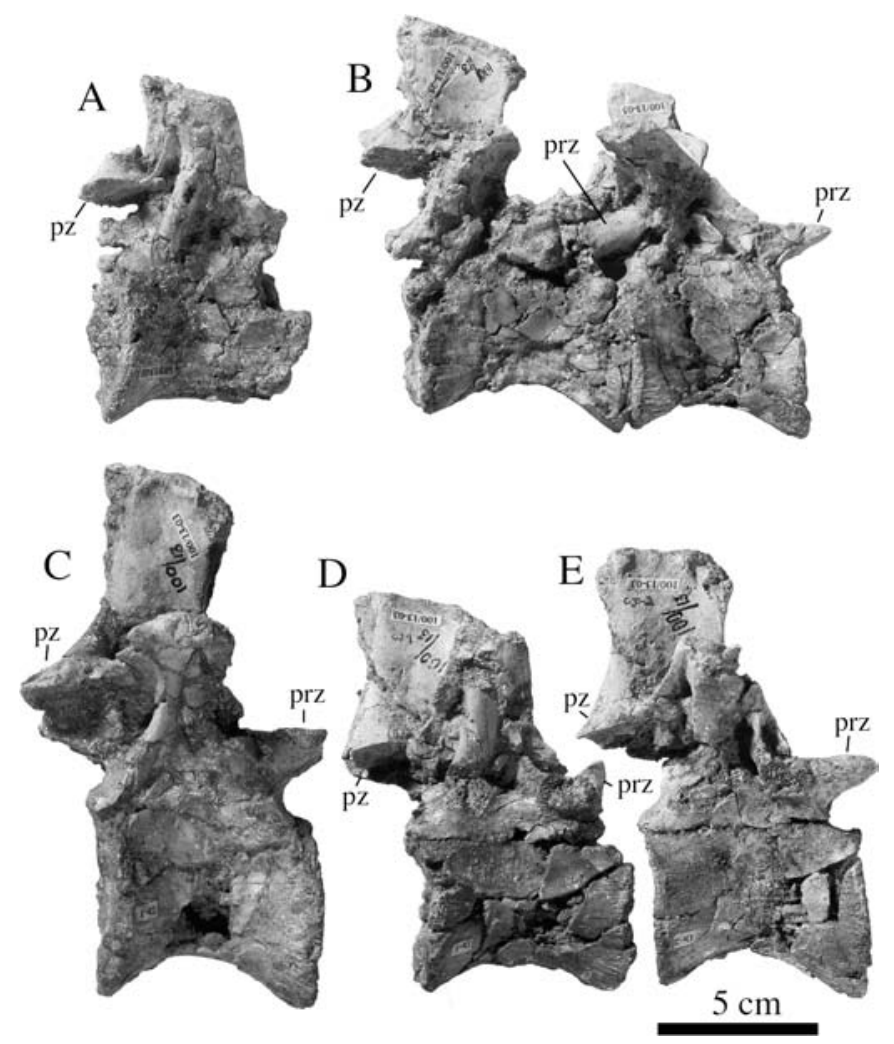

pterygoid is thin and long as in G. bullatus (Parks 1928; Osmólska et al. 1972). The quadrate flange of the pterygoid is transversely oriented, nearly perpendicular to the main body of the pterygoid, and overlaps the medial surface of the pterygoid wing of the quadrate. The basipterygoid process of the pterygoid is short. The main body of the ectopterygoid has a ventral opening for a pneumatopore, illustrated as a fenestra by Barsbold (1981) (Figs. 4B, 4E). The anterolateral edge of the main body bears a jugal hook, as in allosauroids, tyrannosaurids, and Deinonychus (Figs. 3A, 3D). The tip of the jugal hook fits on the medioventral surface of the jugal. The ectopterygoid has no contact with the lacrimal, unlike Oviraptor (Elzanowski 1999).

\section{Mandible}

\section{Dentary}

The edentulous dentary is complete and well preserved. The dentary is the longest of the mandibular elements $(183 \mathrm{~mm})$ and deepens posteriorly. The anterior part of the dentary shows a ventral deflection forming the gap between the upper and lower jaws. The dorsal border of the dentary has a well-developed cutting edge, extending posteriorly for roughly $70 \mathrm{~mm}$ (Figs. 2B, 2E, 4C, 4F). The dorsal edge of the dentary, anterior (ventrally reflected region) and posterior to the cutting edge, is rounded transversely. Foramina are present on the lateral surface of the dentary in the ventrally reflected region and along the symphysis (Figs. 2B, 2E). The symphysis is not complexly structured, indicating that the 
Table 2. Centrum lengths of cervical, dorsal, sacral, and caudal vertebrae of G. brevipes (GIN 100/13).

\begin{tabular}{ll}
\hline Element & Length $(\mathrm{mm})$ \\
\hline Axis & 32 \\
Cervical 4 & $(66)^{a}$ \\
Cervical 8 & 64 \\
Dorsal 4 & 36 \\
Dorsal 5 & 39 \\
Dorsal 6 & 42 \\
Dorsal 7 & 47 \\
Dorsal 8 & 52 \\
Dorsal 9 & 47 \\
Dorsal 10 & 54 \\
Dorsal 11 & 51 \\
Dorsal 12 & 52 \\
Sacral 1 & 50 \\
Sacral 2 & 54 \\
Sacral 3 & 51 \\
Sacral 4 & 45 \\
Sacral 5 & 56 \\
Sacral 6 & 54 \\
Caudal 1 & 47 \\
Caudal 2 & 49 \\
Caudal 3 & 48 \\
Caudal 4 & 47 \\
\hline
\end{tabular}

${ }^{a}$ Length of neural arches.

interdentary articulation was not rigid. The medial surface has a Meckelian groove, covered by the splenial. The groove narrows anteriorly but extends farther anteriorly than in G. bullatus (to the ventral symphysis). Dorsal to the symphysis, the medial surface of the dentary forms a shovel-like shelf (Figs. 4C, 4F). The shelf is widest and deepest at the symphysis. The dentary has three posterior processes, one each at the posterodorsal and posteroventral corners of the element and one at the anterior edge of the external mandibular fenestra (Figs. 2B, 2E). A short process from the posterodorsal end laps onto the lateral side of the surangular, as in Struthiomimus sp. (TMP 90.26.1), and the dentary-surangular suture is $\mathrm{W}$-shaped. A process from the posteroventral end is short as well and contacts the anterior process of the angular along a $\mathrm{W}$-shaped suture. The contact is positioned rostral to the middle of the external mandibular fenestra, unlike that in Struthiomimus sp. (TMP 90.26.1), in which it is posterior to the mid-length of the fenestra. The process at the anterior edge of the external mandibular fenestra is dorsoventrally tall as in H. okladnikovi (GIN 100/29).

\section{Splenial}

The splenial covers the entire Meckelian groove, unlike that in G. bullatus (Hurum 2001), and is deepest at the posterior end of the cutting edge of the mandible and narrows anteriorly (Figs. 2C, 2F; 3C, 3F). The posterior edge of the element is concave and tilted anteriorly in medial view. The posterior end thins out ventral to the prearticular.

\section{Surangular}

The surangular is the second longest mandibular element. The dorsal process of the surangular is shallow with respect
Fig. 9. Ilia and sacral vertebrae of G. brevipes (GIN 100/13) in dorsal (A), right lateral (B), ventral (C), anterior (D), and posterior (E) views. atr, antitrochanter; bf, brevis fossa; cf, cuppedicus fossa; isp, ischiac peduncle; pup, pubic peduncle; sac, supraacetabular crest; sv, sacral vertebra.

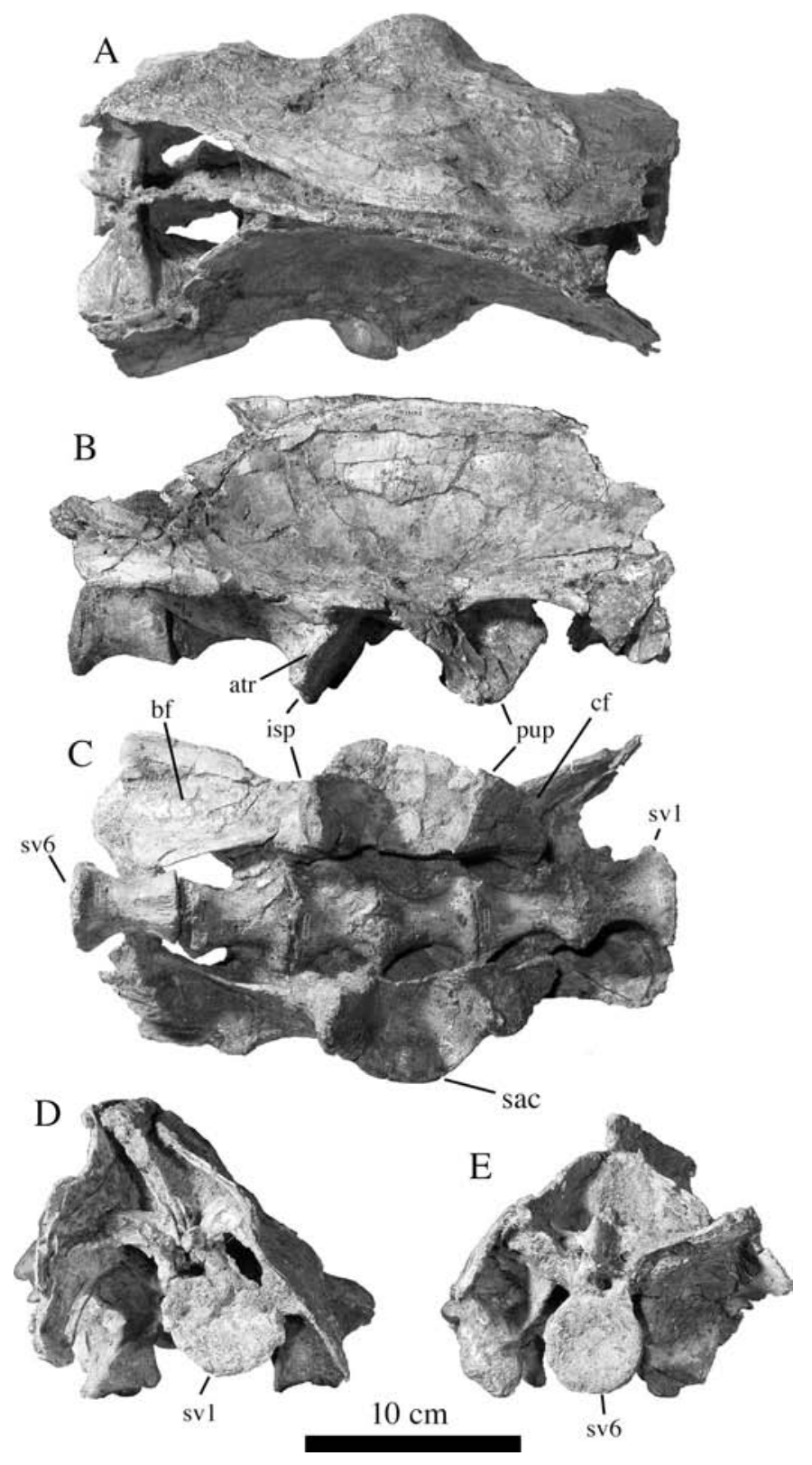

to the length of the process (breadth at the base of the process is $13.2 \mathrm{~mm}, 32.5 \mathrm{~mm}$ long) unlike the deep process of Struthiomimus sp. (TMP 90.26.1). The process extends farther anteriorly than the anterior edge of the mandibular fenestra by $13.2 \%$ of the total mandibular length, whereas this relationship is $9.9 \%$ in Struthiomimus sp. (TMP 90.26.1). The dorsal edge of the surangular forms a medial shelf along its full length (Figs. 3C, 3F). The dorsal edge of the surangular, posterior to the external mandibular fenestra, has a ridge for articulation with the accessory mandibular condyle of the quadrate (Figs. 4C, 4F). The surangular lacks a posterior surangular foramen as in H. okladnikovi (GIN 100/29) but 
Fig. 10. Anterior caudal vertebrae of G. brevipes (GIN 100/13): first caudal in lateral view (C), second caudal in lateral (B) and ventral (A) views, third caudal in lateral view (E), and fourth caudal in lateral view (D). (F, G) Dorsolateral views of the bases of neural spines of (E) and (C), respectively, showing depressions (dep). prz, prezygapophysis; pz, postzygapophysis.
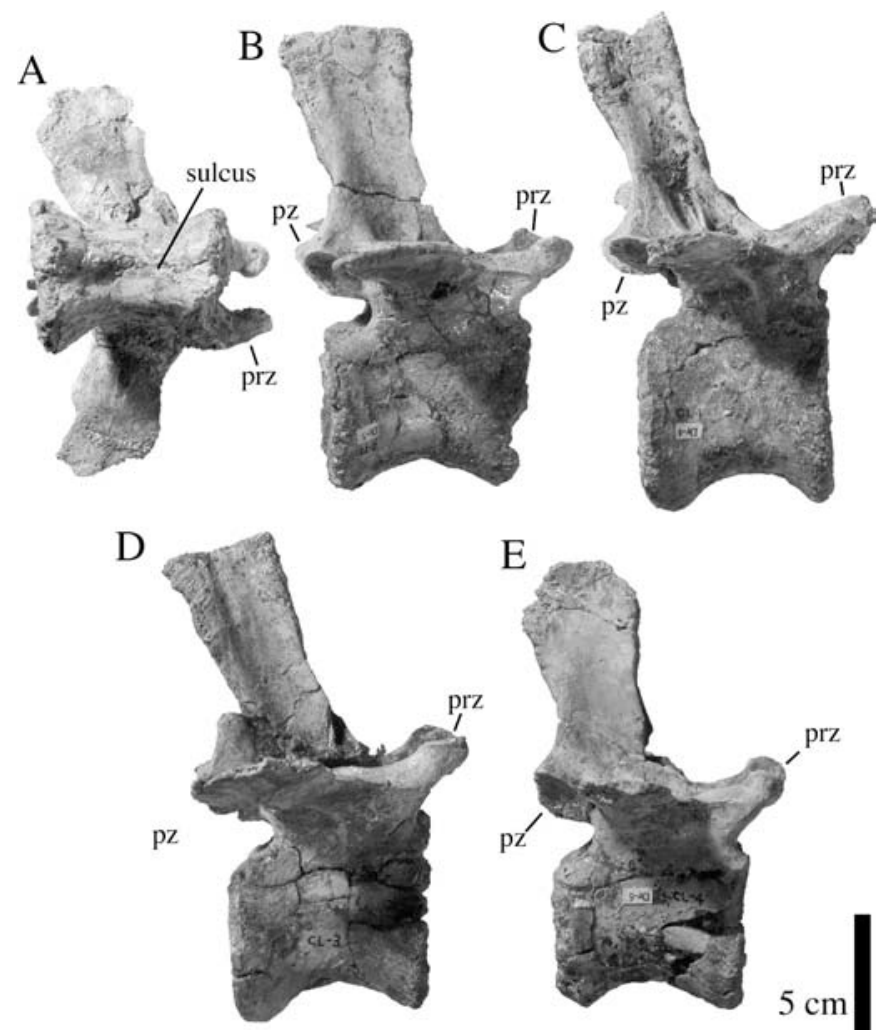

E
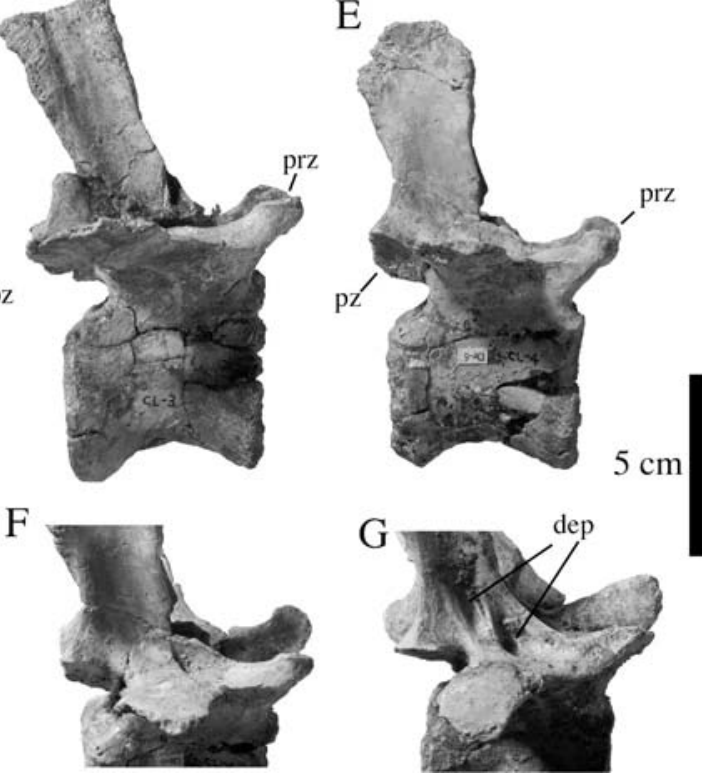

unlike G. bullatus. The surangular participates in only the anterior half of the lateral surface of the retroarticular process. The retroarticular process points slightly upward at its posterior tip as in Ornithomimus sp. (TMP 95.110.1) and Struthiomimus sp. (TMP 90.26.1).

\section{Angular}

The angular is shorter than the surangular and borders the external mandibular fenestra posteroventrally (Figs. 2B, 2E, $3 \mathrm{~B}, 3 \mathrm{E})$. The straight angular-surangular suture extends from the posterior end of the external mandibular fenestra to the posterior end of the mandible. The anterior process is long and contacts the dentary.

\section{Prearticular}

The prearticular is long anteroposteriorly, but is much shorter than that in G. bullatus (Hurum 2001) because it lacks the anterior extension observed in the latter taxon (Figs. 3C, 3F). The anterior end of the element lies posterior to the anterior edge of the external mandibular fenestra and
Fig. 11. Dorsal ribs (A-D) and gastralia (E, F) of G. brevipes (GIN 100/13). c, capitulum; tu, tuberculum.
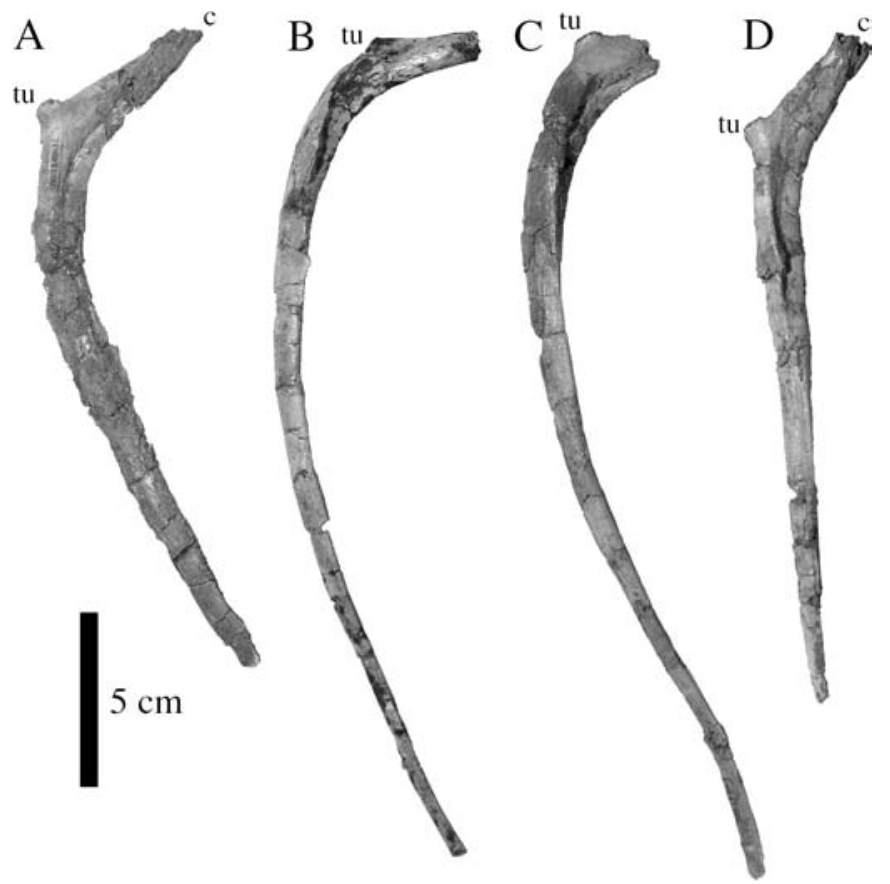

$\mathrm{E}$

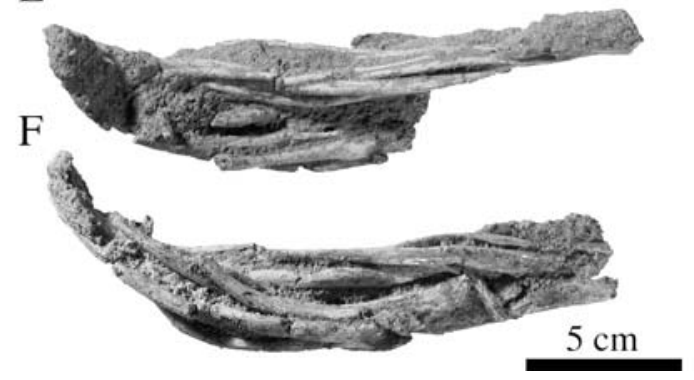

is restricted posteriorly much more than in G. bullatus. The posterior half of the element has an anteroposteriorly oriented sulcus.

\section{Articular}

The articular surfaces for the mandibular condyles of the quadrate are well separated by a ridge. The main axes of the depressions and the ridge are oriented anteromediallyposterolaterally (Figs. 4C, 4F). Posterior to the medial depression, there is a deep and large pneumatopore not seen in other ornithomimosaurs. In dorsal view, it is kidney shaped with an anteroposteriorly directed main axis (16.0 $\mathrm{mm}$ long and $10.0 \mathrm{~mm}$ wide).

\section{Vertebral column}

\section{Cervical vertebrae (Fig. 6)}

Garudimimus brevipes has poorly preserved cervical vertebrae that are crushed transversely, and the axis is the only complete vertebra in the cervical series. Seven other partial cervical vertebrae (atlas, 3-6, and two more) are preserved, but the left sides of most cervical vertebrae are weathered away.

A partial atlantal intercentrum is preserved ventral to the 
Fig. 12. Pubes of G. brevipes (GIN 100/13) in right latera (A) and anterior (B) views.
A

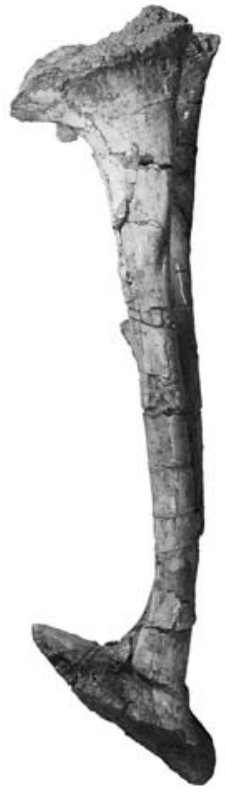

B

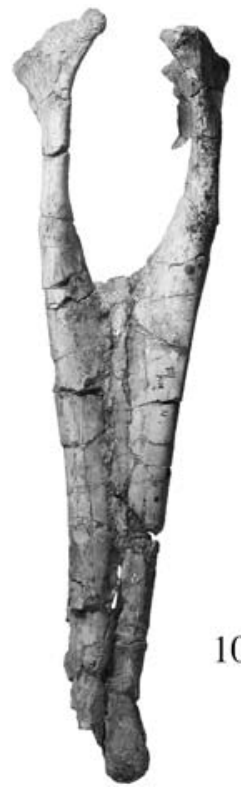

Fig. 13. Right femur of G. brevipes (GIN 100/13) in anterior (A), posterior (B), lateral (C), medial (D), proximal (E), and distal $(\mathrm{F})$ views. actr, accessory trochanter; $\mathrm{ft}$, fourth trochanter; lcd, lateral condyle; lt, lesser trochanter; mcd, medial condyle.

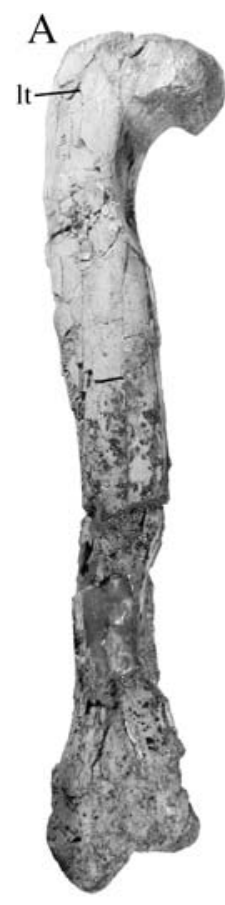

B

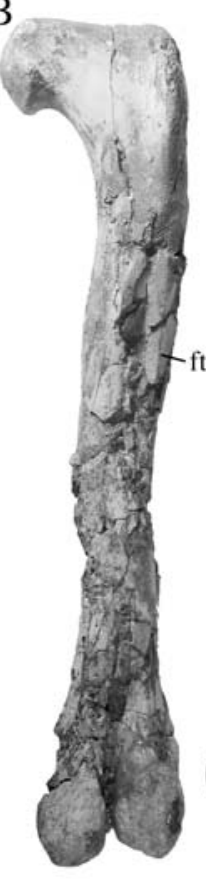

$\mathrm{C} \rightarrow \mathrm{D}$
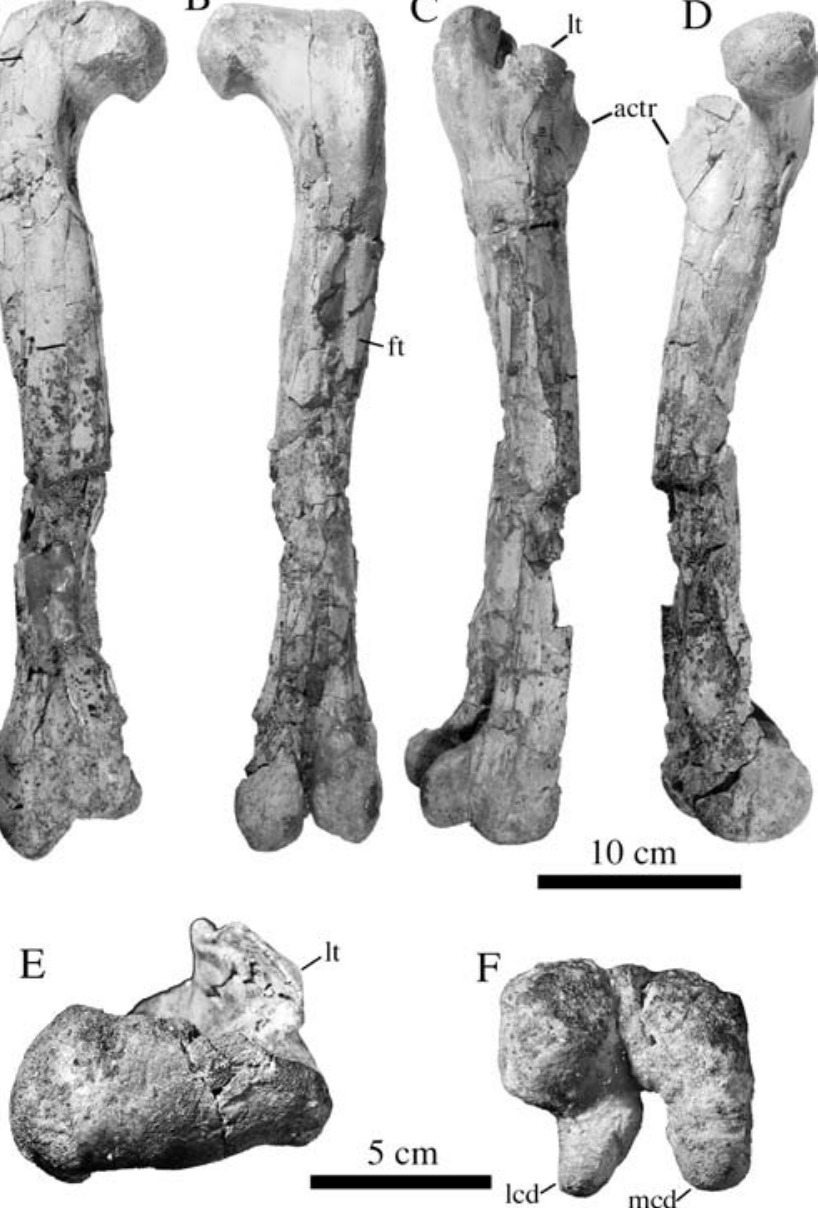

F

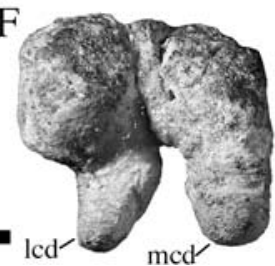
anteriorly, as in Ornithomimus sp. (TMP 93.62.1) (Makovicky 1995), in lateral view. The articular surface is concave and is taller than it is wide. The lateral surface of the centrum lacks a pneumatic fossa. The neural spine is high and rounded, in contrast with that in G. bullatus, which is low and has a flat dorsal edge. The posterior edge of the spine has a posterior ligament scar as in Ornithomimus sp. (TMP 93.62.1) (Makovicky 1995). The articular surface of the postzygapophysis is circular in shape and is horizontal, as in G. bullatus but unlike that in Ornithomimus sp. (TMP 93.62.1), in which it faces more posterolaterally. The epipophysis is weak compared to that in Ornithomimus sp. (TMP 93.62.1) and G. bullatus. The neural arch flares posteriorly in dorsal view and has a pneumatic fossa at the midlength of its centrum as in G. bullatus.

Anterior cervicals three to five are articulated and preserve only the right side of the neural arches (Fig. 6B). Only the postzygapophysis of the third and the anterior neural arch of the fifth are preserved. The fourth cervical vertebra is better preserved. The neural spine is low and positioned slightly posterior to the diapophysis and posterior to the mid-length of the neural arch as in the fifth cervical. The ratio of neural spine length to neural arch length is roughly one third, as in A. asiaticus (Makovicky 1995). The prezygapophysis is long and has a convex articular surface as in the fifth cervical, and the postzygapophysis is short and has a weak epipophysis on its lateral surface. The diapophysis is at mid-length of the neural arch, differing from that in G. bullatus and Ornithomimus sp. (TMP 93.62.1), in which it is slightly anterior to the mid-length. In dorsal view, the posterior edge of the neural spine is straight as in the third cervical.

The neural arch of the sixth cervical vertebra preserves the neural spine and the postzygapophyses (Figs. 6D, 6E). The neural spine is low and anteroposteriorly long as in the fourth cervical vertebra. The postzygapophysis is short and has a circular articular surface. Two other cervicals are articulated, but their exact positions are unclear. These have long postzygapophyses, suggesting that they are posterior cervical vertebrae (Fig. 6C). The postzygapophyses are straight unlike those in G. bullatus and Ornithomimus sp. (TMP 93.62.1) where the postzygapophyses curve slightly outward. The lateral side of the postzygapophysis of the anterior of these two cervicals has a weak epipophysis, whereas Ornithomimus sp. (TMP 93.62.1) lacks an epipophysis on the fifth cervical. The presence of the epipophysis indicates that the anterior of these two vertebrae is probably the seventh cervical. The diapophysis and neural spine are 
positioned anterior to the mid-length of the neural arch, and the parapophysis is strong. The infradiapophyseal and infrapostzygapophyseal fossae are present in the more posterior cervical.

\section{Dorsal vertebrae (Figs. 7, 8)}

Nine consecutive dorsal vertebrae are preserved and probably represent the fourth to twelfth dorsal vertebrae based on the description of Ornithomimus sp. (TMP 93.62.1) (Makovicky 1995). The neurocentral sutures are not completely fused, suggesting that the holotype of $G$. brevipes is not fully mature. Neural spines are preserved in the fifth and seventh to twelfth dorsal vertebrae. The neural spines become progressively taller in more posterior dorsal vertebrae, but their anteroposterior lengths are roughly equal. In lateral view, all neural spines are slightly inclined posteriorly except the twelfth (in which it is anteriorly inclined). Distally, the neural spine flares in the eighth dorsal, but the distal expansion in the ninth to twelfth dorsals is insignificant. The posterior side of each of the neural spines bears a hyposphene. The prezygapophyses and postzygapophyses are short and have circular articular surfaces. The transverse processes up to the ninth dorsal are angled posteriorly, but those of the tenth to twelfth dorsal vertebrae are close to perpendicular to the sagittal plane. The infraprediapophyseal lamina becomes weaker and the infraprezygapophyseal fossa is smaller in posterior dorsals. The infraprezygapophyseal fossa of the sixth dorsal vertebra is divided into two fossae by an accessory lamina, as in Ornithomimus sp. (TMP 93.62.1) (Makovicky 1995). The infradiapophyseal fossa becomes larger as the infraprezygapophyseal fossa becomes smaller posteriorly. The diapophyses are circular and are 8.6 and $13.5 \mathrm{~mm}$ long anteroposteriorly in the fourth and tenth dorsals, respectively. The dorsal centra are longer and taller in more posterior vertebrae and are amphicoelous (Table 2). The intervertebral articular surfaces are oval (higher than wide) and are perpendicular to the main axis of the centrum in lateral view. The lateral surfaces lack pneumatization. On the ventral surfaces in the fourth and fifth dorsal centra, there are median keels extending from anterior to posterior edges, such as seen in the fifth dorsal vertebra of $S$. orientalis (Ji et al. 2003), the first five dorsal vertebrae of $H$. okladnikovi (GIN 100/29) (Kobayashi and Barsbold 2005), and the fourth dorsal vertebra of Ornithomimus sp. (TMP 93.62.1) (Makovicky 1995) (Fig. 7). However, the dorsals of $G$. brevipes lack hypapophyses in contrast with those in Ornithomimus sp. (TMP 93.62.1). The posterior ends of the ventral surfaces in the fifth and sixth dorsal vertebrae have paired weak prominences as in the sixth to eighth dorsal centra of Ornithomimus sp. (TMP 93.62.1) (Makovicky 1995). The anterior and posterior edges of the lateral surface of the centra have ligament scars.

\section{Sacral vertebrae (Fig. 9)}

Garudimimus brevipes has six sacral vertebrae. The first and sixth sacral vertebrae have sacral ribs attached to the medial surface of the ilium. The third and fourth sacral vertebrae are positioned between the pubic and ischiac peduncles. The anteroposterior length of the sacrum is roughly equal to that of the ilium. The lengths of the sacral centra are roughly equal, except for the fourth one (Table 2).
Fig. 14. Articulated left tibiotarsus of G. brevipes (GIN 100/13) in anterior (A), posterior (B), lateral (C), medial (D), proximal (E), and distal (F) views. ast, astragalus; cal, calcaneum; fi, fibula; fif, fibular fossa; pr, prominence; ti, tibia.
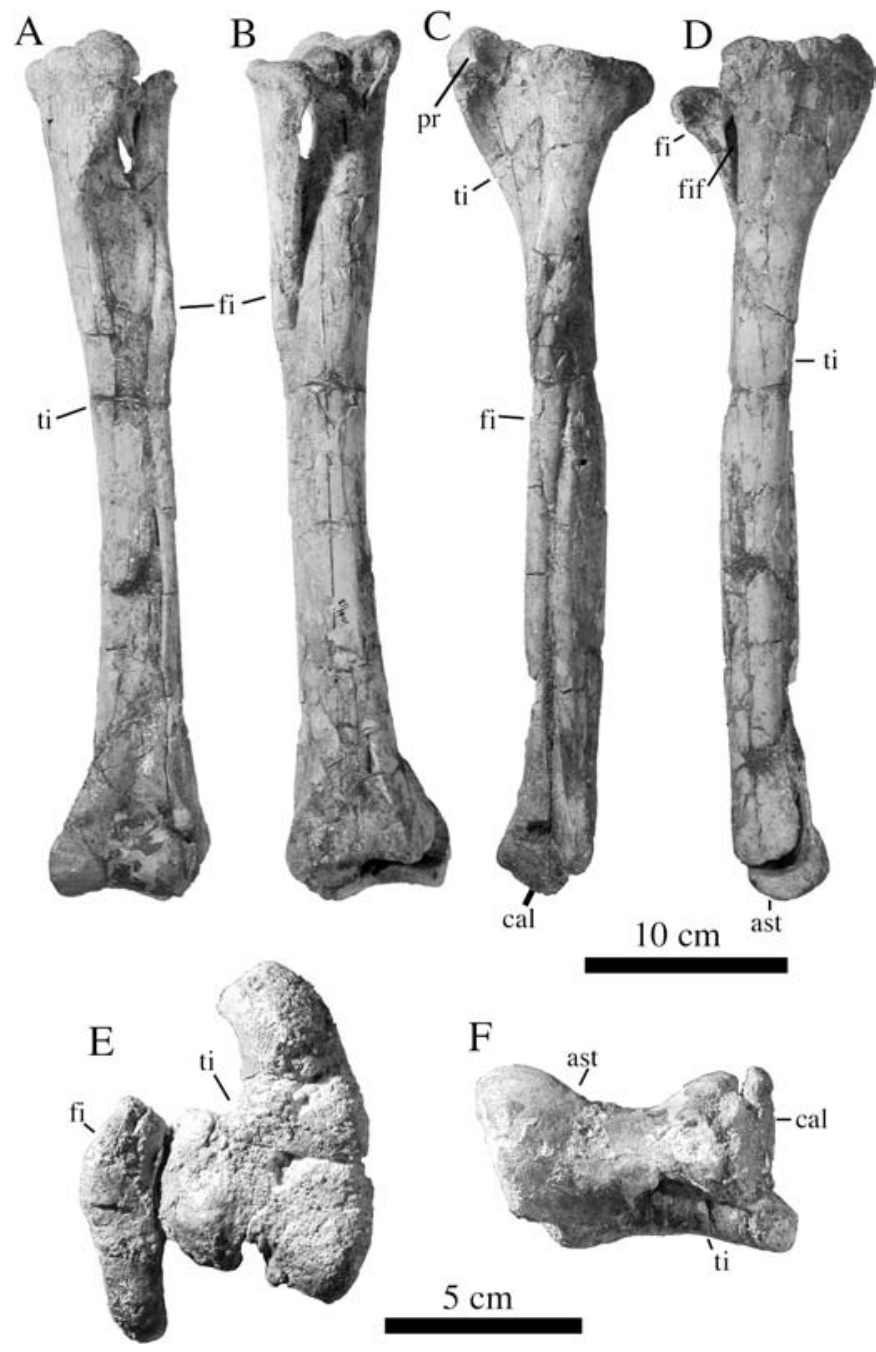

The first and second and the third and fourth sacrals are fused, but other intervertebral articular surfaces remain unfused. The neural spines of the first to fifth sacral vertebrae are fused into a single plate that ends at the level of the dorsal border of the ilium. The neural spine of the sixth is missing, however. The first sacral vertebra is similar to the last dorsal vertebra in having a short prezygapophysis with nearly horizontal articular surfaces, smooth lateral and ventral surfaces of the centrum, and an arched ventral border of the centrum in lateral view. The transverse process of the first sacral vertebra is anteroposteriorly wide and is anteriorly tilted. The process attaches to the medial surface of the ilium, differing from that in G. bullatus, where there is no contact (Osmólska et al. 1972). The ventral surface of the transverse process has a weak ridge, which might be the reduced infrapostdiapophyseal lamina. The transverse process of the sixth sacral is massive and anteroposteriorly wide with a ridge on the dorsal surface. The transverse processes of the fifth and sixth sacrals contact the dorsal side of the medial crest on the brevis fossa of the ilium. 
Fig. 15. Left distal tarsal and metatarsals (II-V) of G. brevipes (GIN 100/13) in anterior (A), posterior (B), lateral (C), medial (D), distal (E), and proximal (F) views. dt, distal tarsal; 1, articular surface for metatarsal I; mt, metatarsal.
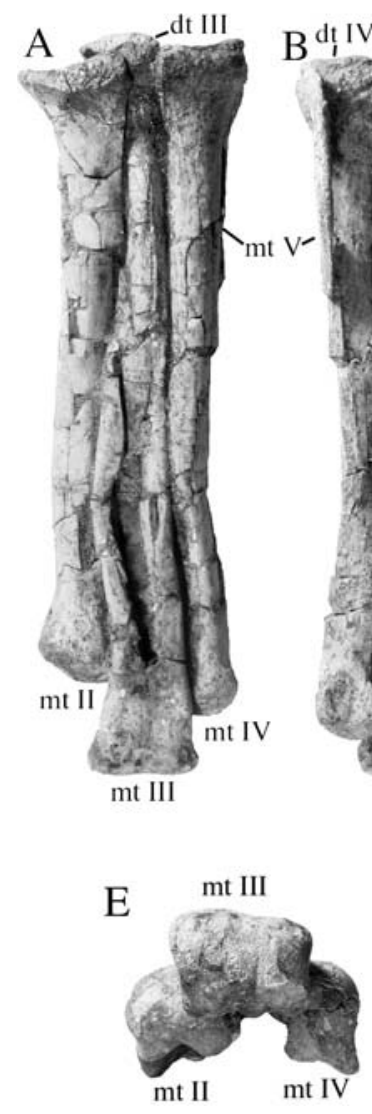

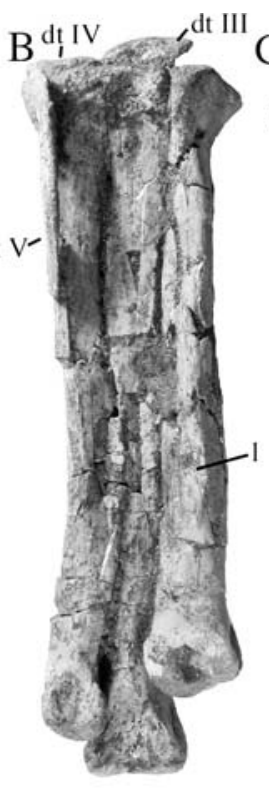

(n)
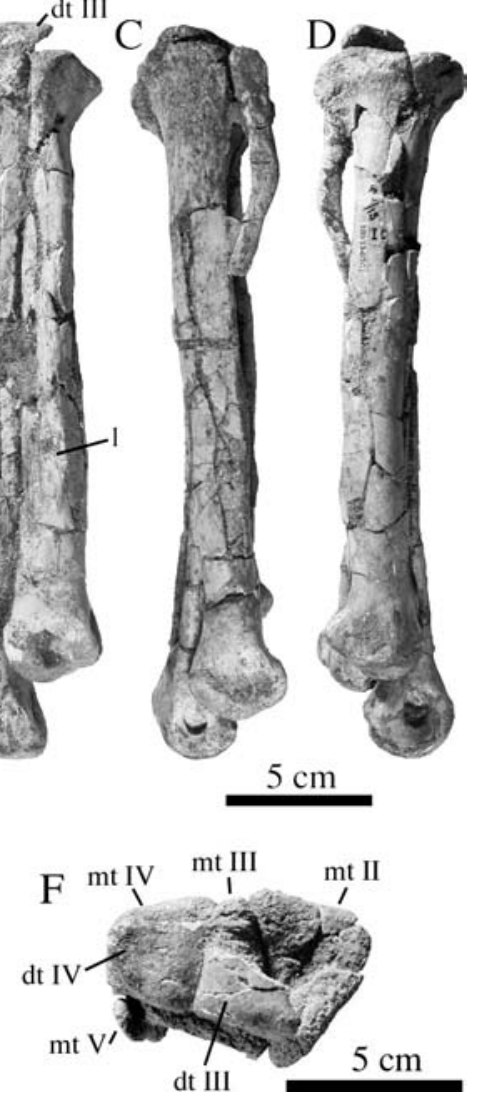

The lateral surfaces of the second to fifth sacral vertebrae are not well exposed. The second sacral centrum is similar to the first sacral and last dorsal vertebra but differs in having a low centrum posteriorly. The third and fourth sacral centra are wide. The third sacral centrum has a depression on the lateral surface, as seen in the second to fifth sacral centra of Ornithomimus sp. (TMP 93.62.1) (Makovicky 1995) and in the third and fourth sacral centra of S. orientalis (Ji et al. 2003). The ventral surface of the fourth sacral centrum has a shallow sulcus, as seen in the third and fourth sacral centra of Ornithomimus sp. (TMP 93.62.1) (Makovicky 1995). The anterior portion of the fifth sacral centrum is much wider than the posterior end because of the presence of the process for the suture with its sacral rib. The ventral surface of the fifth sacral centrum has a weak median ridge and a pair of prominences at the posterior end of the ventral surface. The sixth sacral centrum has smooth lateral surfaces without pneumatization. The posterior intervertebral articulation of the centrum is circular in posterior view. The ventral surface of the centrum has a pair of weak ridges on the anterior half. In lateral aspect, the anterior edges of the first and sixth sacral vertebrae and the posterior edges of the fifth and sixth sacral vertebrae have ligament scars. The postzygapophyses of the sixth sacral vertebra are short.
Fig. 16. Left metatarsal I (mt 1) and digit I (I-1, I-2) of G. brevipes (GIN 100/13) in anterior (A), posterior (B), medial (C), and lateral (D) views.
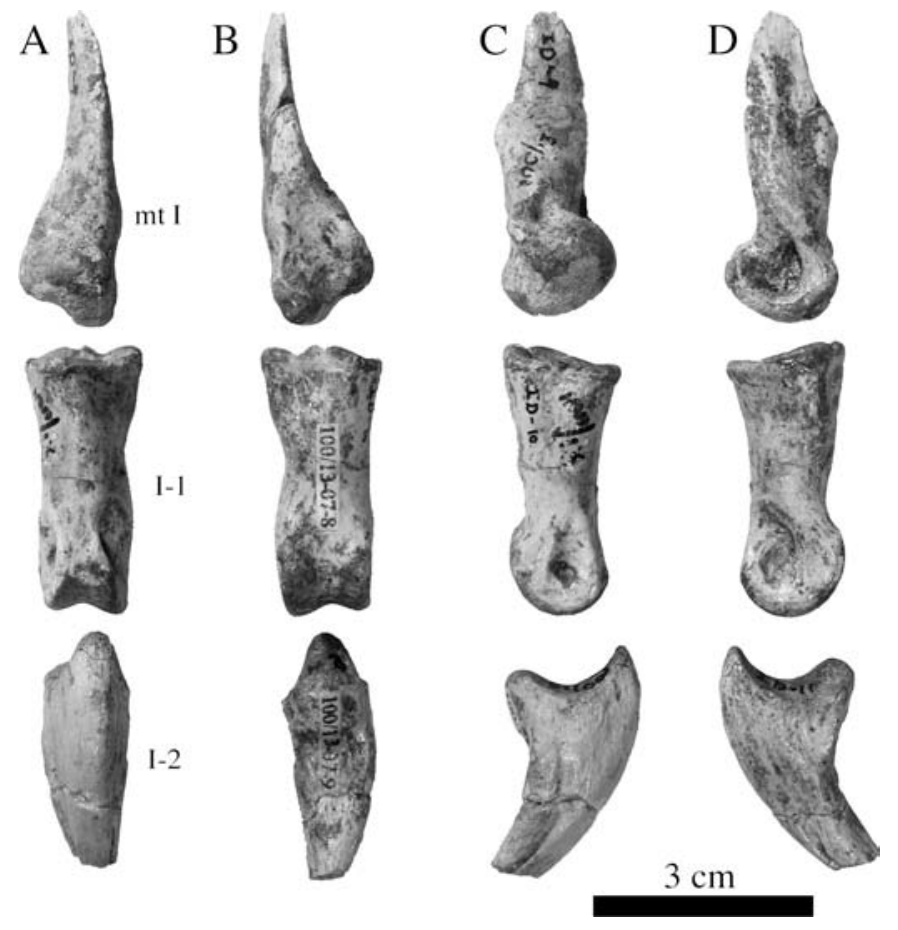

\section{Caudal vertebrae (Fig. 10)}

The first four proximal caudal vertebrae are preserved and all neurocentral sutures are open. The neural spine of the first caudal vertebra is the tallest, and they become shorter posteriorly. The main axis of the spine is tilted posteriorly. The neural spines flare dorsally and have straight and horizontal dorsal borders. The anterior and posterior edges of the spine are grooved. At the bases of the neural spine and transverse process of the first caudal vertebra, two depressions are present, separated by a thin lamina (Figs. 10C, 10G). The anterior depression is triangular and deeper than the posterior one. The anterior depression is present in the other preserved caudals but becomes less pronounced posteriorly. The posterior depression is visible in the second caudal vertebra as a faint depression and is further diminished in the other two. The prezygapophyses and postzygapophyses are short and their articular surfaces are angled roughly $45^{\circ}$ from the horizontal. The transverse processes are long and slightly directed posteriorly. The lengths of the centra are equal. The caudal vertebrae have paired prominences on either side of the sulci for articulation with the chevrons.

\section{Ribs and gastralia}

The posterior part of the third cervical rib and the anterior part to the fourth rib are preserved (Fig. 6). The posterior end of the third cervical rib extends to the posterior end of the corresponding centrum, and the anterior part of the fourth is triangular in lateral view. Nine dorsal ribs are preserved and each has a short tuberculum and long capitulum (Figs. 11A11D). The shaft of the rib has anterior and posterior extensions as other ornithomimosaurs. The distal ends are squared as in the anterior dorsal ribs of $S$. altus. Sacral ribs are not 
well exposed. Fifteen segments of gastralia are preserved, but their exact positions are unknown (Figs. 11E, 11F). The gastralia in $G$. brevipes are segmented into at least two parts (lateral and medial) as in S. altus (Nicholls and Russell 1981) and other non-ornithurine theropods and prosauropods (Claessens 2004). Paired lateral and medial gastralia thin towards each other and overlap. The lateral gastralia are thinner than the medial gastralia, and the medial gastralia are expanded for articulation with the gastralia of the other side.

\section{Appendicular skeleton}

\section{Pelvic girdle and hind limbs}

The pelvic girdle is preserved, but both ischia are missing. Hind limb elements are well preserved, but the right limb distal to the tarsals is missing.

\section{Ilium (Fig. 9)}

Both ilia are slightly crushed. The dorsal edges of the ilia lie close to each other as in other ornithomimids (Makovicky et al. 2004) and some oviraptorosaurs (Barsbold et al. 2000; Lü et al. 2002). The antilium has a ventrally projecting hook. The ischiac peduncle is wedge-shaped, pointed in lateral view, and wide in ventral view as in other ornithomimosaurs. The brevis fossa, bounded by the brevis shelf laterally and medial crest medially, is as large as in other ornithomimosaurs but is shallow. The ventral edge of the lateral crest is straight in lateral view, as in other ornithomimosaurs, except $S$. orientalis (Ji et al. 2003). The medial crest becomes stronger posteriorly. The cuppedicus fossa along the ventral border of antilium is much shorter and narrower than the brevis fossa.

\section{Pubis (Fig. 12)}

The pubis is longer than the anteroposterior length of the ilium. It is slightly longer than the femur as in Anserimimus planinychus but unlike that in $G$. bullatus and the North American taxa. In lateral view, the proximal end of the left pubis has a ventrally extending hook on the ventral edge of the pubis-ischium contact. Its shaft is nearly straight, in contrast with the situation in A. asiaticus. The aprons on the medial surfaces of the paired shafts meet one third of the total length of the element $(130 \mathrm{~mm})$ from the proximal end of the pubis. The posterior extension of the pubic boot is longer than the anterior extension as in ornithomimids. The paired pubic boots are partially separated at their anterior ends and are fused posteriorly. In lateral view, the ventral border of the pubic boot is nearly straight, as in other Asian ornithomimids, but unlike that in S. orientalis (Ji et al. 2003).

\section{Femur (Fig. 13)}

The right femur is less crushed than the left femur. In proximal view, the anteroposterior length of the femur head is more than half of the transverse width of the proximal end, unlike the condition in other ornithomimosaurs. The anterior border of the lesser trochanter has an accessory trochanter as in most ornithomimosaurs (Makovicky et al. 2004). The accessory trochanter is strong, and there is a sulcus between the lesser and accessory trochanters. The fourth trochanter is positioned at roughly one third $(31 \%)$ of the femur length from the proximal end. The intercondylar groove at the distal end is deep. The tibial articular protuberance of the lateral
Table 3. Measurements of the pelvic girdle and hind limb elements of $G$. brevipes (GIN 100/13).

\begin{tabular}{lll}
\hline Element & Length $(\mathrm{mm})$ & Width $(\mathrm{mm})$ \\
\hline Ilium & 287 & - \\
Pubis & 390 & - \\
Femur & 371 & 79 \\
Tibia & 388 & 52 \\
Fibula & 360 & 18 \\
Astragalus & 110 & 66 \\
Calcaneum & 21 & 11 \\
Metatarsal I & 43 & 14 \\
Metatarsal II & 195 & 34 \\
Metatarsal III & 229 & 22 \\
Metatarsal IV & 212 & 27 \\
Metatarsal V & 71 & 6 \\
Phalanx I-1 & 35 & 15 \\
Phalanx I-2 & $33^{a}$ & 11 \\
Phalanx II-1 & 63 & 29 \\
Phalanx III-1 & 59 & 35 \\
Phalanx III-2 & 45 & 26 \\
Phalanx IV-1 & 43 & 23 \\
Phalanx IV-2 & 35 & 21 \\
Phalanx IV-3 & 28 & 19 \\
Phalanx IV-4 & 27 & 18 \\
Phalanx IV-5 & 46 & 14 \\
\hline Note: The width &
\end{tabular}

Note: The widths of all elements are measured transversely at the proximal ends, except the astragalus and metatarsal I at the distal end.

${ }^{a}$ Element incomplete, minimum value.

condyle projects posteriorly unlike that in $S$. dongi (Kobayashi and Lü 2003).

\section{Tibia (Fig. 14)}

The left tibia is less crushed than the right tibia. The ratio of tibiotarsus length (408 mm) to femur length is 1.1 (Table 3). The proximal end has equally developed lateral and medial posterior condyles and a long anterior process, which curves laterally. The dorsal border of the anterior process has a prominence also seen in S. dongi (Kobayashi and Lü 2003). The posterolateral corner of the distal end has a strong ridge, as in H. okladnikovi (GIN 100/29) (Kobayashi and Barsbold 2005).

\section{Fibula (Fig. 14)}

The fibula is slightly shorter than the tibia. The proximal part is transversely flattened. The posterior border of the proximal end has a ridge unlike that in S. dongi (Kobayashi and Lü 2003). The medial surface of its proximal end has a depression (fibular fossa). The shaft is thin (11.6 mm compared with $60.5 \mathrm{~mm}$ at the proximal end). The distal end contacts the anterior side of the tibia and lateral side of the astragalus.

\section{Tarsals (Fig. 14)}

The left side preserves both astragalus and calcaneum, but the calcaneum is damaged. The ascending process of the astragalus is complete and its length is less than one third of the tibia length (Table 3). 
Fig. 17. Left pedal phalanges (II-IV) of G. brevipes (GIN 100/13) in anterior (A), posterior (B), lateral (C), and medial (D) views. dep, depression.

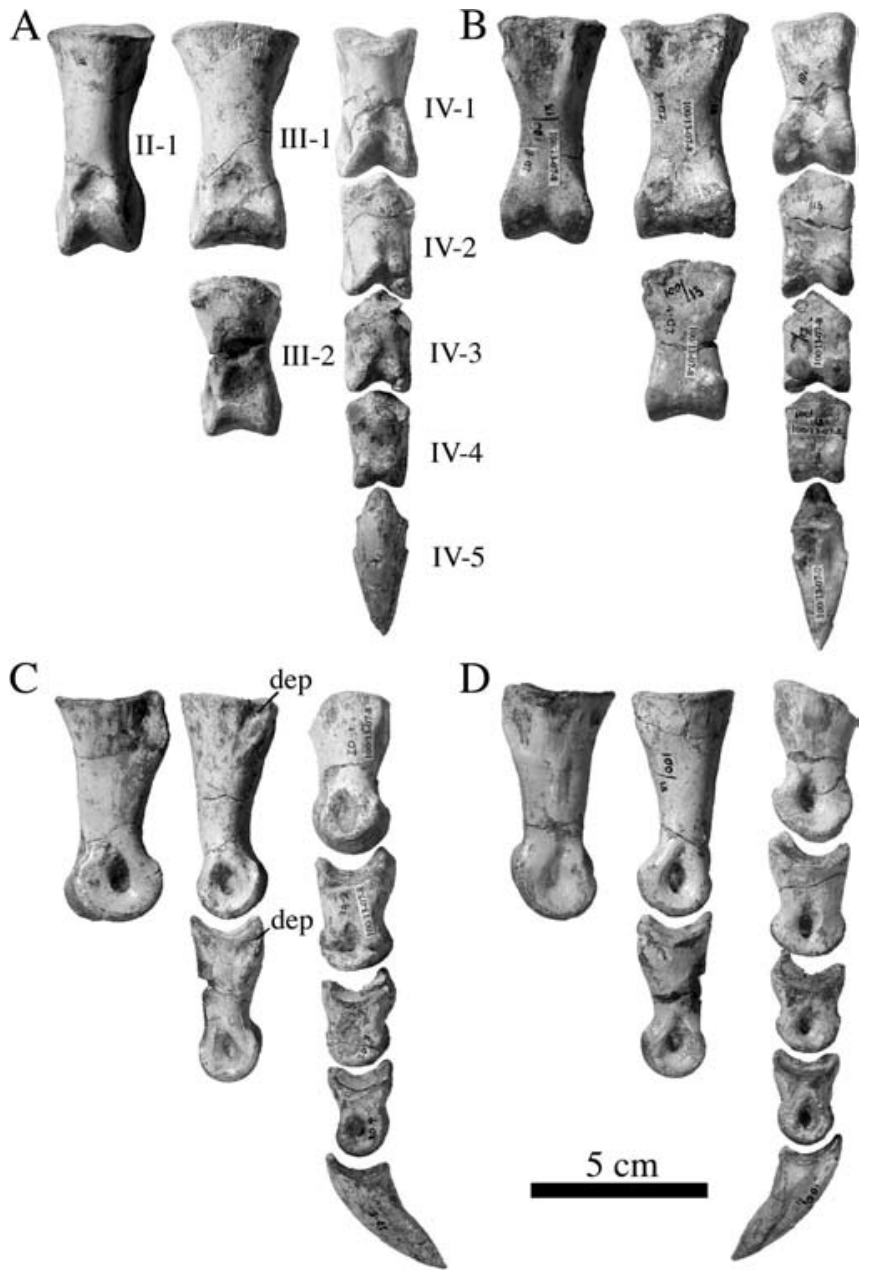

\section{Distal tarsals (Fig. 15)}

Distal tarsals III and IV are preserved. Distal tarsal III is incomplete, missing its anterior portion, and articulates mainly with the proximal surface of metatarsal III and partially with metatarsal II. Distal tarsal IV covers most of the area of the proximal surface of metatarsal IV. The posterolateral corner of the element is convex in proximal view, unlike that of H. okladnikovi (GIN 100/29), which is concave.

\section{Metatarsals (Figs. 15, 16)}

Garudimimus brevipes has five metatarsals and four digits. Metatarsal I is only one fifth of the length of metatarsal III (Table 3). The phalangeal articular surface is rounded. The posterior surface of the distal end has two reduced condyles, separated by an intercondylar groove. The lateral collateral ligament fossa is deeper than the medial. Proximally, metatarsal I is flat and its lateral surface is slightly convex for its contact with metatarsal II. The flat articular surface of metatarsal II for metatarsal I is positioned on the posterior surface of metatarsal II. Metatarsals II and IV are subequal in length (Table 3). The distal ends of metatarsals II and IV are similar to that of metatarsal I in having a rounded distal articular surface and reduced condyles posteriorly. The distal
Fig. 18. Left metatarsals with articulated digit I of $G$. brevipes (GIN 100/13) in lateral (A, D), posterior (B, E), and medial (C, F) views. (A) to $(\mathrm{C})$ are flexion condition, and $(\mathrm{D})$ to $(\mathrm{F})$ are extension condition. dt, distal tarsal; mt, metatarsal; I-1, pedal phalanx I-1; I-2, pedal phalanx I-2.
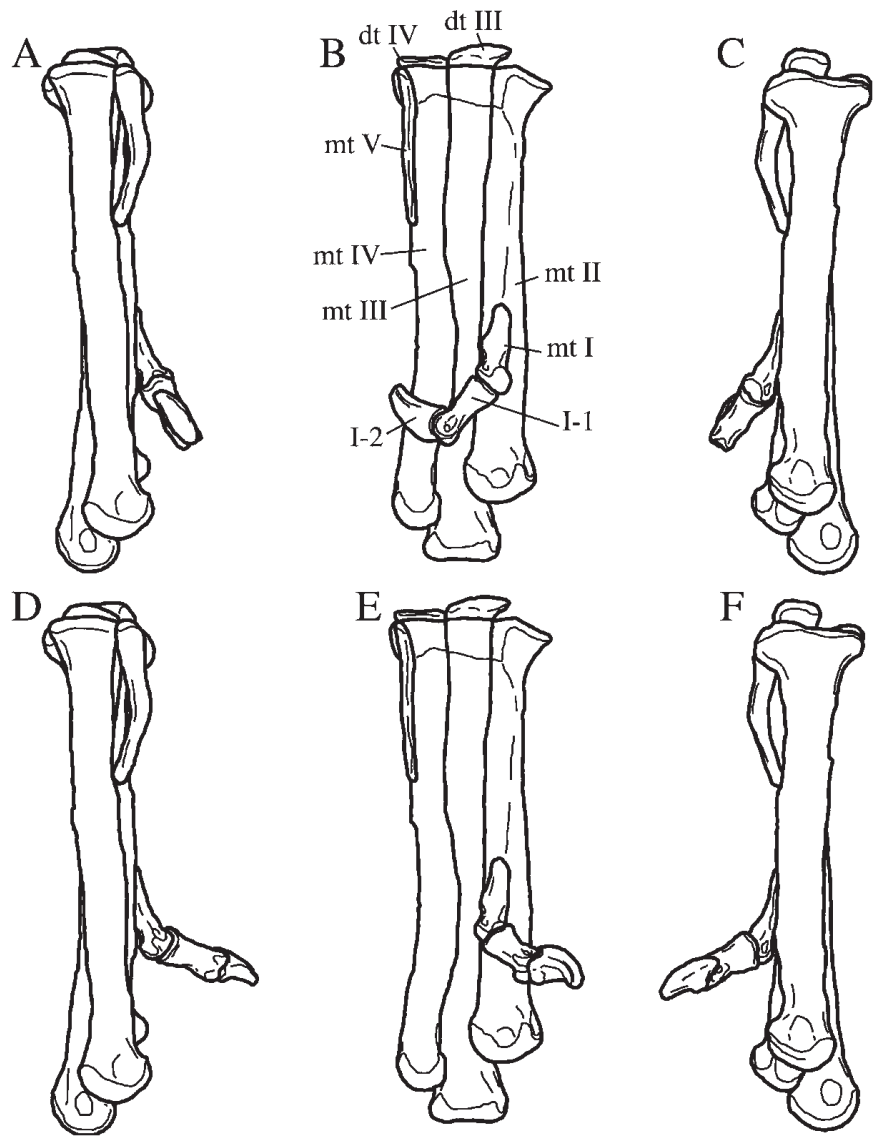

end of metatarsal III is wider transversely than anteroposteriorly. The collateral ligament fossae are deep, except for the lateral one of metatarsal IV. The proximal end of metatarsal III is exposed anteriorly as in $H$. okladnikovi (Barsbold and Perle 1984). Metatarsal V is reduced and thin as in other ornithomimosaurs. Its proximal end is thickest and transversely flattened. The shaft is bent at mid-length. The distal end is thicker than the shaft as in $S$. dongi (Kobayashi and Lü 2003) but unlike Gallimimus (distal end is thinner). It articulates with the posterior surface of metatarsal IV.

\section{Pedal phalanges (Figs. 16, 17)}

Ten left phalanges (I-1, I-2, II-1, III-1, III-2, and IV-1 to IV-5) are preserved. The most proximal phalanges of all digits have a single concave proximal surface, whose anteroposterior length is close to its width, except in III-1 (wider than long). Phalanx I-1 has deep collateral ligament fossae, and its distal condyles are asymmetrical. Phalanx II-1 is slightly longer than phalanx III-1 and is the longest of the pedal phalanges. Phalanx II-1 is similar to IV-1 in having unevenly developed distal condyles and collateral ligament fossae (the lateral one is larger and deeper in II-1), but is much longer 
Table 4. Measurements (in mm) of the pubis (PU), ilium (IL), femur (FE), metatarsal II (Mt II), metatarsal III (Mt III), and metatarsal IV (Mt IV) in ornithomimosaurs.

\begin{tabular}{lllllll}
\hline Taxon & PU & IL & FE & Mt II & Mt III & Mt IV \\
\hline Shenzhousaurus orientalis & 169 & 153 & 191 & - & - & - \\
Harpymimus okladnikovi & - & - & - & 292 & 310 & 304 \\
Garudimimus brevipes & 390 & 287 & 371 & 195 & 229 & 212 \\
Archaeornithomimus asiaticus (AMNH) & - & - & - & 257 & 287 & 262 \\
Sinornithomimus dongi (IVPP-V11797-10) & 330 & 268 & 323 & - & 213 & 197 \\
Sinornithomimus dongi (IVPP-V11797-23) & - & - & 190 & 116 & 128 & 121 \\
Gallimimus bullatus (GIN 100/11) & 690 & - & 685 & 475 & 525 & 495 \\
Gallimimus bullatus (GIN 100/12) & 485 & 495 & 505 & 345 & 365 & 340 \\
Gallimimus bullatus (GIN 100/10) & 195 & 195 & 190 & 144 & 160 & 147 \\
Gallimimus bullatus (GIN 100/14) & 433 & 431 & 391 & 244 & 267 & 250 \\
Gallimimus sp. (GIN 950818) & 451 & 496 & 456 & 275 & 312 & 291 \\
Anserimimus planinychus & 465 & 480 & 435 & 265 & 295 & 280 \\
Struthiomimus altus (UCMZ(VP)1980.1) & 476 & 480 & 500 & 290 & 320 & 295 \\
Struthiomimus altus (ROM 1790) & 327 & 375 & 386 & 278 & 294 & 284 \\
Ornithomimus edmontonicus (ROM 851) & 411 & 398 & 435 & 295 & 317 & 302 \\
Ornithomimus sp. (TMP 95.110.1) & 440 & 409 & 425 & 302 & 337 & 312 \\
Dromiceiomimus brevitertius (ROM 797) & 394 & - & 387 & 272 & 292 & 283 \\
Dromiceiomimus brevitertius (ROM 852) & - & 450 & 423 & 327 & 372 & 346 \\
\hline
\end{tabular}

Note: These measurements are used for the graphs in Fig. 19.

than IV-1. Pedal phalanx III-1 is distinct from the other first phalanges because it is nearly symmetrical, is wider than long, has deep collateral ligament fossae, and has a shallow intercondylar groove. Phalanx III-2 is similar to III-1 but is shorter. Furthermore, its proximal border in anterior view is more convex. Pedal phalanges III-1 and III-2 have a short but deep groove at the proximal end of the lateral surface unlike H. okladnikovi (GIN 100/29), where this surface is smooth. Phalanges IV-2 to IV-4 are similar to IV-1 except that in each of these the proximal surface is divided into two by a vertical ridge. The phalanges become shorter from IV-2 to IV-4. The lateral ligament fossae of phalanges IV-1 to IV-4 are shallower than the medial fossae but are much deeper than those in H. okladnikovi (GIN 100/29). Ungual phalanx IV-5 has a strong flexor tubercle as in H. okladnikovi (GIN 100/29). Ungual phalanx I-2 shows similarities to IV-5 but is asymmetrical, with its main axis curved laterally. It has a strong flexor tubercle and a shallow depression on the lateral surface of the proximal end.

\section{Discussion}

Some of the characters used by Barsbold (1981) in his diagnosis of Garudimimus (short ilia, short metatarsals, exposure of the proximal end of metatarsal III, presence of pedal digit I, and absence of pleurocoels) may not be useful. Phylogenetic analyses by Kobayashi and Lü (2003) and Makovicky et al. (2004) indicate that the proximal exposure of metatarsal III is a plesiomorphy within Ornithomimosauria and that pneumatic structures in the sacral vertebrae are absent in some other ornithomimosaurs (Garudimimus brevipes, Gallimimus bullatus, and Struthiomimus altus). The presence of metatarsal I and digit I is probably not an autapomorphy for $G$. brevipes. A primitive ornithomimosaur from the Early Cretaceous of Mongolia (the Huren-duh ornithomimosaur, GIN 960910KD) possesses metatarsal I and digit I (Kobayashi and Barsbold 2002). The arrangement and movement of metatarsal I and digit I in G. brevipes are similar to those in other theropods (Fig. 18), which probably suggests that the presence of metatarsal I and digit I is a primitive condition in Ornithomimosauria and the absence of these elements in H. okladnikovi could be because of lack of preservation.

Barsbold (1981) used the ilia being shorter than the pubes and short metatarsals as diagnostic characters of G. brevipes. Although it is true that the anteroposterior length of the ilium of $G$. brevipes is less than the length of the pubis, this is common in ornithomimosaurs (Table 4). The ratio of ilium length to pubis length is distinctly smaller in $G$. brevipes than in other ornithomimosaurs, however (Fig. 19A). Shenzhousaurus orientalis and $S$. dongi also have small ratios, but these fall between the values for $G$. brevipes and those for late Late Cretaceous ornithomimids. An allometric equation, derived from Table 4, is (ilium length $) /($ pubis length $)=0.0003 \times$ (femur length) +0.8382 and shows a poor correlation between the changes in ratios with femur length $\left(R^{2}=0.100\right)$. This indicates that a short ilium is probably significant taxonomically and may be plesiomorphic within Ornithomimosauria, because Garudimimus, Shenzhousaurus, and Sinornithomimus are basal to other ornithomimosaurs listed in Table 4.

The ratio of metatarsal III length to femur length is smallest in G. brevipes (Fig. 19B), but the ratios are also small $(<0.7)$ in other ornithomimosaurs (Sinornithomimus, Gallimimus, Anserimimus, and Struthiomimus). This suggests that the shortness of the metatarsals of $G$. brevipes compared with other ornithomimosaurs is not diagnostic for the genus but simply the retention of ancestral non-ornithomimosaur theropod metatarsal proportions for typical forms of that body size (Holtz 1994). Little changes in hind limb proportions with increasing body size are suggested by Osmólska et al. (1972) and Russell (1972). The scatterplot in Fig. 19B shows nearly no linear relationship and indicates that differ- 
Table 5. Comparisons of the ratios of postorbital length to skull length measured in the anteroposterior direction.

\begin{tabular}{llll}
\hline Taxon & Skull length $(\mathrm{mm})$ & Postorbital length $(\mathrm{mm})$ & Postorbital length to skull length $(\%)$ \\
\hline Garudimimus brevipes (GIN 100/13) & 252 & 46.3 & 18.4 \\
Ornithomimus sp. (TMP 95.110.1) & 236 & 39.6 & 16.8 \\
Struthiomimus sp. (TMP 90.26.1) & 215 & 32.6 & 15.2 \\
\hline
\end{tabular}

Table 6. Measurements of metatarsal III length (Mt III), length from the distal end to the medial expansion in metatarsal III (DE-ME), and comparisons of the ratios of DE-ME to Mt III.

\begin{tabular}{llll}
\hline Taxon & Mt III (mm) & DE-ME (mm) & Ratio (\%) \\
\hline Harpymimus okladnikovi & 310 & 135 & 0.436 \\
Garudimimus brevipes & 229 & 81 & 0.354 \\
Gallimimus sp. (GIN 100/14) & 271 & 78 & 0.288 \\
\hline
\end{tabular}

ences in the ratios of metatarsal III length to femur length may not be related to their ontogenetic stages.

A long postorbital region of the skull relative to other ornithomimosaurs was suggested as a diagnostic trait of Garudimimus by Currie (2000). Postorbital length is slightly less than $20 \%$ of total skull length in G. brevipes, which is similar to Ornithomimus sp. (TMP 95.110.1) and Struthiomimus sp. (TMP 90.26.1) (Table 5). The jaw articulation of G. brevipes is more posteriorly positioned than the postorbital bar as suggested by Currie (2000), which differs from other ornithomimosaurs, in each of which the jaw articulation is ventral to the postorbital bar in $H$. okladnikovi (GIN 100/29), G. bullatus, Ornithomimus sp. (TMP 95.110.1), and Struthiomimus sp. (TMP 90.26.1). Because of the posterior position of the mandibular condyle of the quadrate, the posterior edge of the skull is nearly vertical in G. brevipes, whereas the edges in H. okladnikovi (GIN 100/29), G. bullatus, Ornithomimus sp. (TMP 95.110.1), and Struthiomimus sp. (TMP 90.26.1) are tilted anteroposteriorly.

Currie and Eberth (1993) suggested that metatarsals of A. asiaticus (AMNH 6565) from the Iren Dabasu Formation of China belong to Garudimimus because of the presence of arctometatarsalian pes and pes digit I and the proportions of metatarsal elements (II, III, and IV). They interpreted that Garudimimus has the arctometatarsalian pes because the Garudimimus metatarsals are crushed and metatarsal III is recessed from the extensor surface of metatarsus. The original specimen shows little crushing, however, especially at both extremities (Fig. 15). In proximal view, the proximal end of metatarsal III is clearly exposed on the extensor surface of metatarsus, and there is no contact between metatarsals II and IV (Figs. 20A, 20D). The contact surfaces of metatarsal III with metatarsals II and IV are straight in proximal view, whereas these are curved, corresponding to the shape of the proximal end of metatarsal III, in Archaeornithomimus and other derived ornithomimosaurs with the arctometatarsalian pes (Figs. 20A, 20B). These differences suggest that Garudimimus metatarsus clearly has the non-arctometatarsalian pes and that Archaeornithomimus metatarsus has the arctometatarsalian pes. The presence of pes digit I in Archaeornithomimus, mentioned by Currie and Eberth, is based on the description of Archaeornithomimus by Smith and Galton (1990), who noted that the medial surface of metatarsal II has a concave surface for metatarsal I. As suggested earlier, metatarsal II of Garudimimus has a contact surface for metatarsal I on the posterior surface of metatarsal II; therefore, Smith and Galton may have misidentified the contact surface. The presence or absence of digit I cannot be confirmed until additional material of Archaeornithomimus is found. The ratios of metatarsal II length to metatarsal III length and metatarsal IV length to metatarsal III length of Garudimimus are compared with ratios in other ornithomimosaurs (Fig. 19C). The ratios of metatarsal IV length to metatarsal III length of Garudimimus and Archaeornithomimus are close, but the ratios of metatarsal II length to metatarsal III length are different (shorter metatarsal II in Garudimimus than in Archaeornithomimus). Because of the differences in the ratios of metatarsal II length to metatarsal III length and arctometatarsalian condition versus non-arctometatarsalian condition, metatarsals of Archaeornithomimus (AMNH 6565) do not belong to Garudimimus.

Currie (2000) stated that the degree of constriction of the proximal end of metatarsal III is intermediate between that of H. okladnikovi (GIN 100/29) and that of other species of ornithomimids. The proximal end of metatarsal III is covered by metatarsals II and IV (arctometatarsalian condition) in all ornithomimids (A. asiaticus, A. planinychus, G. bullatus, Ornithomimus edmontonicus, D. brevitertius, and S. altus), and phylogenetic analyses by Kobayashi and Lü (2003) and Makovicky et al. (2004) suggest that this is one of the synapomorphies for Ornithomimidae (Fig. 21). The proximal end of metatarsal III in G. brevipes is exposed (nonarctometatarsalian condition) as in H. okladnikovi (GIN 100/29) and the Huren-duh ornithomimosaur (GIN 960910KD) (Kobayashi and Barsbold 2002; Kobayashi and Barsbold 2005). In anterior view, the shaft of metatarsal III has a medial expansion (Figs. 20C-20E). The proximodistal length from the distal end of metatarsal III to the medial expansion in G. brevipes is less than that in H. okladnikovi (GIN 100/29) but greater than that in Gallimimus sp. (GIN 100/14) (Table 6), which is an intermediate step towards an arctometatarsalian condition as suggested by Currie (2000).

A phylogenetic analysis by Kobayashi and Barsbold (2004), in turn based on a data matrix of Kobayashi and Lü (2003), which includes all 11 recognized genera of Ornithomimosauria, supports the monophyly of Garudimimus and Ornithomimidae with five unambiguous synapomorphies (long maxillary process of premaxilla, nearly equal exposed area of prefrontal 
Fig. 19. Graphs of femur length versus ratio of ilium length to pubis length (A), femur length and ratio of metatarsal III length to femur length (B), and ratio of metatarsal II length to metatarsal III length versus ratio of metatarsal IV length to metatarsal III length (C) from Table 4.

A

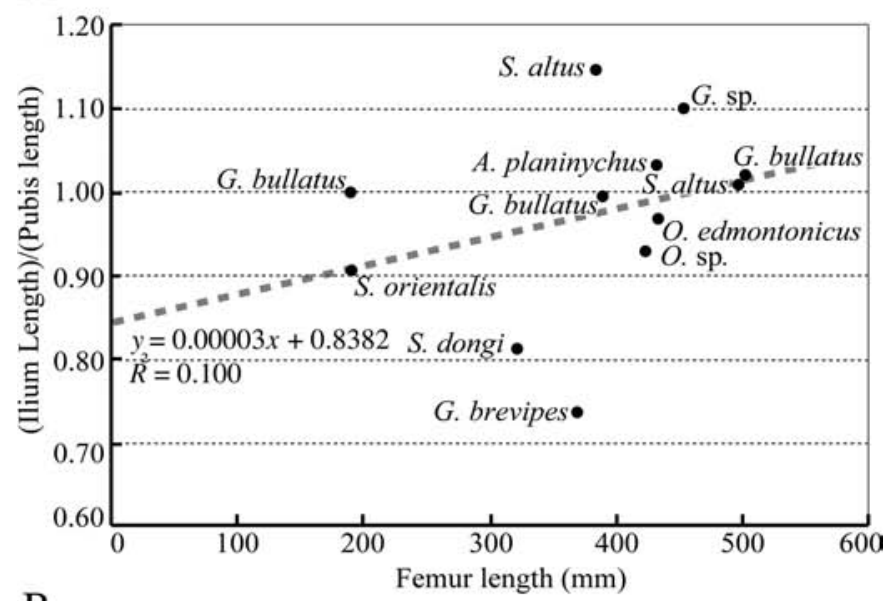

$\mathrm{B}$

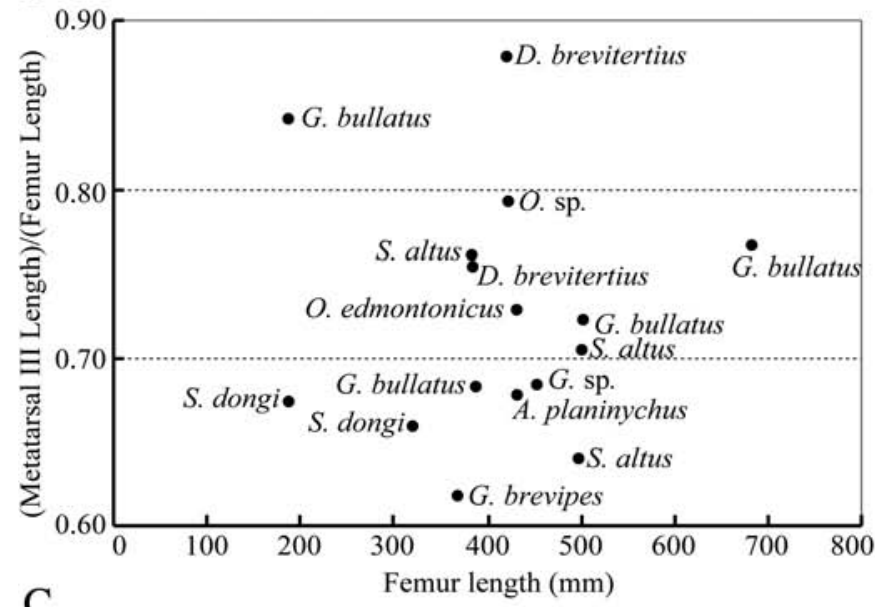

$\mathrm{C}$

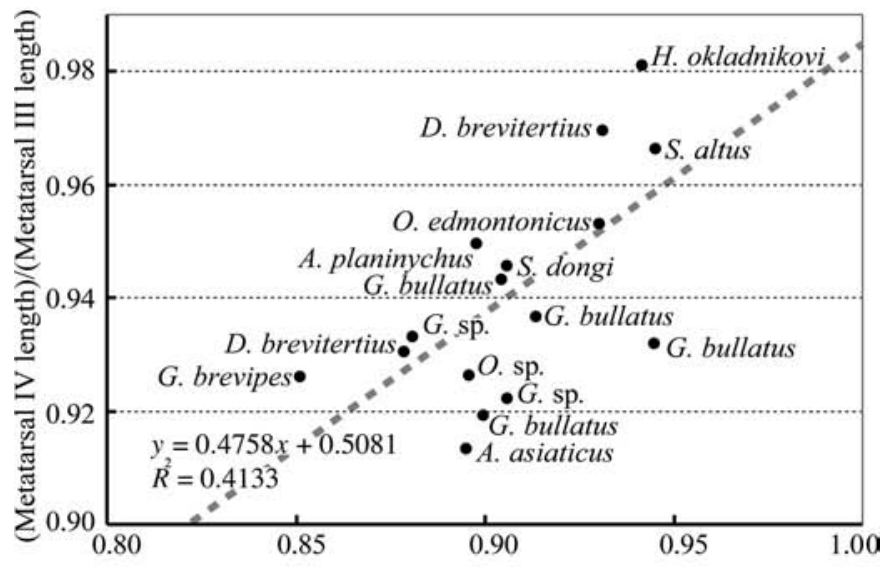

(Metatarsal II length)/(Metatarsal III length)

and lacrimal in dorsal view, loss of dentary teeth, cutting edge of dentary, length of pedal phalanx II-2 less than $60 \%$ of that of pedal phalanx II-1). This clade is supported by some skull features, which may be related to the changes in feeding (Fig. 21). The loss of dentary teeth and acquisition of a sharp edge of the dentary may indicate that the food processing of $G$. brevipes differs from toothed ornithomimosaurs (Pelecanimimus polyodon, $H$. okladnikovi, and $S$. orientalis) but is similar to that of the members of Ornithomimidae. The anterior parts of the upper and lower jaws of $G$. brevipes were both probably covered by rhamphothecae as in ornithomimids (Norell et al. 2001) and may have been used for plucking food. The sharp-edged middle portions of the jaws were used for cutting food. Pelecanimimus polyodon has a large number of minute teeth in both upper and lower jaws with no interdental space unlike that in any other ornithomimosaurs, but Pérez-Moreno et al. (1994) suggested that the arrangement of teeth in this taxon may have been used for cutting and ripping, similar to that of ornithomimids. Derived ornithomimosaurs may have used the anterior portion of the jaws for different purposes besides plucking food, such as filtering food (plants and invertebrates) from water in Gallimimus (Norell et al. 2001). Differences in the beak shapes of North America taxa (pointed and narrow beak) compared to those of some Asian taxa (rounded and wide beak) may also suggest adaptions for various feeding habitats in ornithomimosaurs (Kobayashi and Lü 2003; Makovicky et al. 2004).

Ornithomimidae is a sister taxon to Garudimimus and shares a single unambiguous synapomorphy (arctometatarsalian pes) (Kobayashi and Lü 2003; Kobayashi and Barsbold 2004) (Fig. 21). Two additional characters (surangular foramen absent, first pedal digit absent) are supported as synapomorphies under ACCTRAN optimization. DELTRAN optimization shows four more possible synapomorphic characters (radial condyle of humerus smaller than ulnar condyle, metacarpal I slightly shorter than metacarpal II, medially rotated distal end of metacarpal I, metacarpal II longer than metacarpal III). Because Garudimimus does not preserve forelimb elements and the skull of the basalmost taxon within Ornithomimidae (Archaeornithomimus) has never been discovered, the character distribution at this node is not well resolved yet. Further discoveries of these taxa will provide better understandings of character distributions.

\section{Acknowledgments}

This paper is a portion of the $\mathrm{Ph}$.D. dissertation of the first author (Yoshitsugu Kobayashi), who would like to acknowledge his committee members, namely Louis L. Jacobs (Southern Methodist University, Dallas, Texas), Dale A. Winkler (Southern Methodist University), Anthony R. Fiorillo (Dallas Museum of Natural History, Dallas, Texas), Philip J. Currie (Royal Tyrrell Museum of Palaeontology), and the coauthor (Rinchen Barsbold) for their guidance during the course of the dissertation. We would like to thank Peter J. Makovicky (Field Museum of Natural History, Chicago, Illinois) and Thomas R. Holtz, Jr. (University of Maryland) for the reviews of this manuscript. We are grateful to Philip J. Currie and Elizabeth L. Nicholls (Royal Tyrrell Museum of Palaeontology), Mark A. Norell (American Museum of Natural History), Peter J. Makovicky, Bernardino P. Pérez-Moreno (Universidad Auton a de Madrid, Spain), Zhi-Ming Dong (Institute of Vertebrate Paleontology and Paleoanthropology, Beijing, China), Kevin Seymour (Royal Ontario Museum), Isao Takahashi (Gobi Support Japan, Kanna, Gunma, Japan), and Kazuhisa 
Fig. 20. Metatarsals of G. brevipes (GIN 100/13) (A) and Archaeornithomimus asiaticus (AMNH 6565) (B) in proximal view. Comparisons of metatarsals of H. okladnikovi (GIN 100/29) (C), G. brevipes (GIN 100/13) (D), and Gallimimus sp. (GIN 100/14) (E) in anterior view. Arrowheads show medial expansions of metatarsal III.
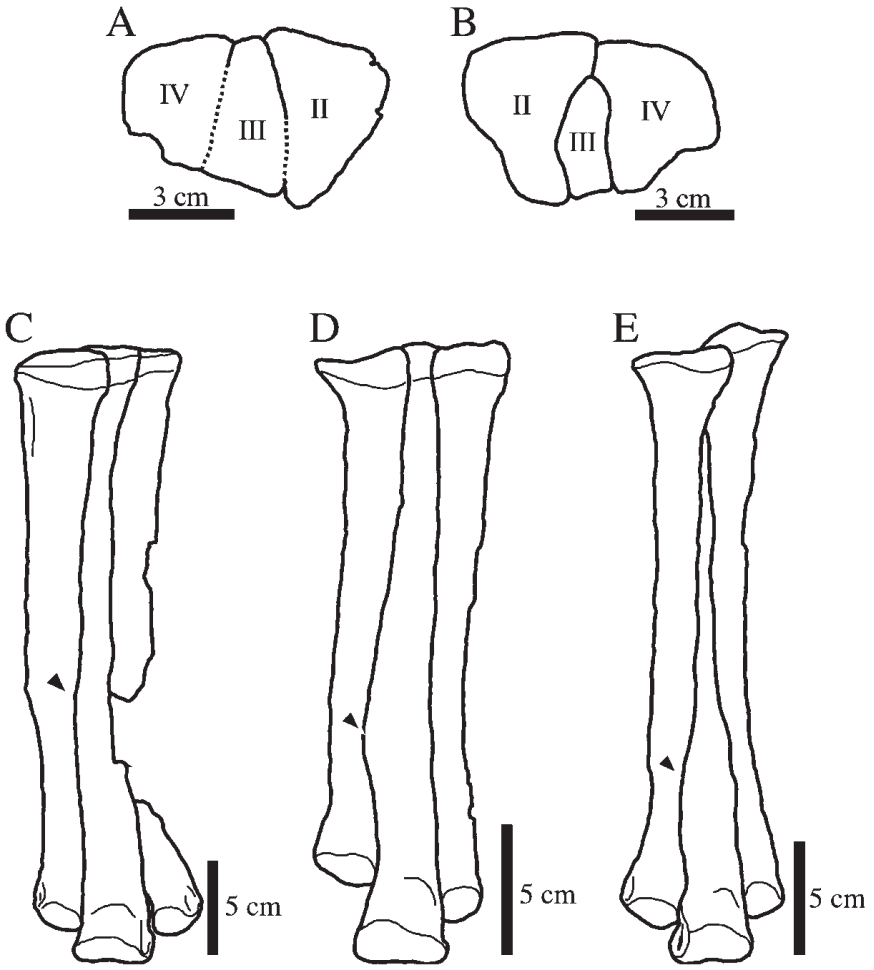

Sato (Kanna Dinosaur Center, Kanna, Gunma, Japan) for providing access to specimens. Financial support was provided by the Institute for the Study of Earth and Man, the Jurassic Foundation, and the Sasakawa Scientific Research Grant.

\section{References}

Barsbold, R. 1976. On the evolution and systematics of the late Mesozoic dinosaurs. Paleontologi i biostratigrafi Mongolii, Sovmestna Svetsko-Mongolska Paleontologiceska Ekspedici Trudy 3, 3: 68-75.

Barsbold, R. 1981. Toothless carnivorous dinosaurs of Mongolia. Transactions, Joint Soviet-Mongolian Palaeontological Expedition, 15: 28-39.

Barsbold, R., and Osmólska, H. 1990. Ornithomimosauria. In The Dinosauria. Edited by D.B. Weishampel, P. Dodson, and H. Osmólska. University of California Press, Berkeley, Calif. pp. 225-244.

Barsbold, R., and Perle, A. 1984. On first new find of a primitive ornithomimosaur from the Cretaceous of the MPR. Paleontologicheskiy Zhurnal, 1984(2): 121-123.

Barsbold, R., Osmólska, H., Watabe, M., Currie, P.J., and Tsogtbaatar, K. 2000. A new oviraptorosaur (Dinosauria, Theropoda) from Mongolia: the first dinosaur with a pygostyle. Acta Palaeontologica Polonica, 45: 97-106.

Claessens, L.P.A.M. 2004. Dinosaur gastralia; origin, morphology, and function. Journal of Vertebrate Paleontology, 24: 89-106.

Currie, P.J. 1985. Cranial anatomy of Stenonychosaurus inequalis
Fig. 21. Cladogram of Ornithomimosauria from Kobayashi and Barsbold (2004), showing the distribution of characters, associated with feeding and arctometatarsalian pes, and the evolution of a rhamphotheca. Arrows in the skulls of Harpymimus and Pelecanimimus show the position of the posteriormost tooth in jaws.

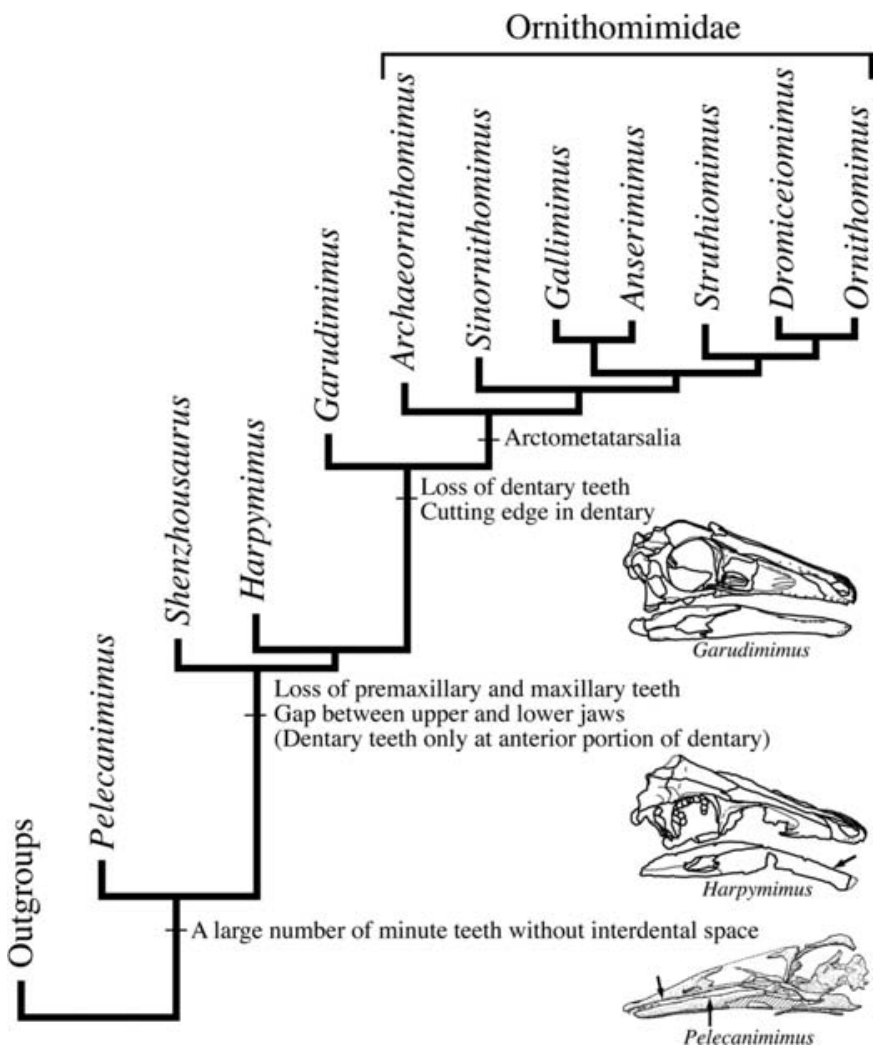

(Saurischia: Theropoda) and its bearing on the origin of birds. Canadian Journal of Earth Sciences, 22: 1643-1658.

Currie, P.J. 1995. New information on the anatomy and relationships of Dromaeosaurus albertensis (Dinosauria: Theropoda). Journal of Vertebrate Paleontology, 15: 576-591.

Currie, P.J. 2000. Theropods from the Cretaceous of Mongolia. In The age of dinosaurs in Russia and Mongolia. Edited by M.J. Benton, M.A. Shishkin, D.M. Unwin, and E.N. Kurochkin. Cambridge University Press, Cambridge, UK., pp. 434-455.

Currie, P.J., and Eberth, D.A. 1993. Palaeontology, sedimentology and palaeoecology of the Iren Dabasu Formation (Upper Cretaceous), Inner Mongolia, People's Republic of China. Cretaceous Research, 14: 127-144.

Currie, P.J., and Zhao, X.-J 1994. A new troodontid (Dinosauria, Theropoda) braincase from the Dinosaur Park Formation (Campanian) of Alberta. Canadian Journal of Earth Sciences, 30: 2231-2247.

Elzanowski, A. 1999. A comparison of the jaw skeleton in theropods and birds, with a description of the palate in the Oviraptoridae. In Avian paleontology at the close of the 20th century, Proceedings of the 4th International Meeting of the Society of Avian Paleontology and Evolution, Washington, D.C., 4-7 June 1996. Edited by S.L. Olsen. Smithsonian Contributions to Paleobiology, 89, pp. 311-323.

Holtz, T.R., Jr. 1994. The arctometatarsalian pes, an unusual structure of the metatarsus of Cretaceous Theropoda (Dinosauria: Saurischia). Journal of Vertebrate Paleontology, 14: 480-519.

Hurum, J.H. 2001. Lower jaw of Gallimimus bullatus. In Mesozoic 
vertebrate life. Edited by D.H. Tanke and K. Carpenter. Indiana University Press, Bloomington, Ind., pp. 34-41.

Ji, Q., Norell, M.A., Makovicky, P.J., Gao, K., Ji, S., and Yuan, C. 2003. An early ostrich dinosaur and implication for ornithomimosaur phylogeny. American Museum Novitates, 3420, 19 p.

Khand, Y., Badamgarav, D., Ariunchimeg, Y., and Barsbold, R. 2000. Cretaceous System in Mongolia and its depositional environments. In Cretaceous environments of Asia. Edited by $\mathrm{H}$. Okada and N.J. Mateer. Elsevier Science BV, Amsterdam, The Netherlands, pp. 49-79.

Kobayashi, Y., and Barsbold, R. 2002. A new primitive ornithomimosaur from the Early Cretaceous of Mongolia and the early evolution of Ornithomimosauria. Journal of Vertebrate Paleontology, 22(Supplement): 75.

Kobayashi, Y., and Barsbold, R. 2004. Phylogeny of Ornithomimosauria and its paleobiogeographic implications. In Proceedings of the 19th International Congress of Zoology, Beijing, China, 23-27 August 2004. China Zoological Society, Beijing, China, pp. $50-52$.

Kobayashi, Y., and Barsbold, R. 2005. Anatomy of Harpymimus okladnikovi Barsbold and Perle 1984 (Dinosauria; Theropoda) of Mongolia. In The carnivorous dinosaurs. Edited by K. Carpenter. Indiana University Press, Indianapolis, Ind., pp. 97-126.

Kobayashi, Y., and Lü, J. 2003. A new ornithomimid dinosaur with gregarious habits from the Late Cretaceous of China. Acta Palaeontologica Polonica, 48: 235-259.

Ksepka, D.T., and Norell, M.A. 2004. Ornithomimosaur cranial material from Ukhaa Tolgod (Omnogov, Mongolia). American Museum Novitates, 3448, 4 p.

Lü, J., Dong, Z., Azuma, Y., Barsbold, R., and Tomida, Y. 2002. Oviraptorosaurs compared to birds. In Proceedings of the 5th Symposium of the Society of Avian Paleontology and Evolution, Beijing, China,1-4 June 2000. Edited by Z. Zhou and F. Zhang. Science Press, Beijing, China, pp. 175-189.

Makovicky, P.J. 1995. Phylogenetic aspects of the vertebral morphology of Coelurosauria (Dinosauria: Theropoda). M.S. thesis, Copenhagen University, Copenhagen, Denmark.

Makovicky, P.J., and Norell, M.A. 1998. A partial ornithomimid braincase from Ukhaa Tolgod (Upper Cretaceous, Mongolia). American Museum Novitates, 3247, 16 p.

Makovicky, P.J., Kobayashi, Y., and Currie, P.J. 2004. Ornithomimosauria. In The Dinosauria. 2nd ed. Edited by D.B. Weishampel, P. Dodson, and H. Osmólska. University of California Press, Berkeley, Calif. pp. 137-150.

Marsh, O.C. 1881. Classification of the Dinosauria. The American Journal of Science, Third Series, 23: 81-86.

Norell, M.A., Makovicky, P.J., and Currie, P.J. 2001. The beaks of ostrich dinosaurs. Nature (London), 412: 873-874.

Nicholls, E.L., and Russell, A.P. 1981. A new specimen of Struthiomimus altus from Alberta with comments on the classificatory characters of Upper Cretaceous ornithomimids. Canadian Journal of Earth Sciences, 18: 518-526.

Osmólska, H. 1997. Ornithomimosauria. In Encyclopedia of dinosaurs. Edited by P.J. Currie and K. Padian. Academic Press, San Diego, Calif. pp. 499-503.

Osmólska, H., Roniewicz, E., and Barsbold, R. 1972. A new dinosaur, Gallimimus bullatus n.gen., n.sp. (Ornithomimidae), from the Upper Cretaceous of Mongolia. Palaeontologica Polonica, 27: 103-143.

Parks, W.A. 1928. Struthiomimus samueli, a new species of Ornithomimidae from the Belly Formation of Alberta. University of Toronto Studies, Geological Series, 26, 24 p.

Pérez-Moreno, B.P., Sanz, J.L., Buscalioni, A.D., Moratalla, J.J., Ortega, F., and Rasskin-Gutman, D. 1994. A unique multitoothed ornithomimosaur dinosaur from the Lower Cretaceous of Spain. Nature (London), 370: 363-367.

Russell, D.A. 1972. Ostrich dinosaurs from the Late Cretaceous of western Canada. Canadian Journal of Earth Sciences, 9: 375-402.

Smith, D., and Galton, P. 1990. Osteology of Archaeornithomimus asiaticus (Upper Cretaceous, Iren Dabasu Formation, People's Republic of China). Journal of Vertebrate Paleontology, 10: 255-265.

Witmer, L.M. 1997. The evolution of the antorbital cavity of archosaurs: a study in soft-tissue reconstruction in the fossil record with an analysis of the function of pneumaticity. Journal of Vertebrate Paleontology, Memoir 3, 17(Supplement 1): 1-73. 